\title{
La discriminación racial o étnica: marco jurídico, formas y protección Racial and ethnic discrimination: regulatory framework, forms and protection
}

\author{
Ángeles Solanes Corella* \\ Universitat de València \\ ORCID ID 0000-0002-4207-6113 \\ angeles.solanes@uv.es
}

Cita recomendada:

Solanes Corella, Á. (2019). La discriminación racial o étnica: marco jurídico, formas y protección. Eunomía. Revista en Cultura de la Legalidad, 17, 35-67.

doi: https://doi.org/10.20318/eunomia.2019.4991

Recibido / received: 30/06/2019

Aceptado / accepted: 06/09/2019

\section{Resumen}

El desarrollo de los instrumentos jurídicos internacionales y europeos relativos a la prohibición de la discriminación racial o étnica ha sido significativo en las últimas décadas. Sin embargo, dicho marco regulatorio necesita un mayor perfeccionamiento e implementación que permita también combatir las nuevas formas de discriminación. En esa línea, este trabajo realiza una revisión crítica de la normativa internacional y europea sobre la materia y establece el estado actual de la cuestión. Desde ese análisis, para consolidar los instrumentos de protección del derecho antidiscriminatorio, se propone fortalecer los estándares jurisprudenciales y desarrollar la función de los organismos especializados para la promoción de la igualdad, con la finalidad de conseguir una lucha contra la discriminación racial o étnica que sea más efectiva y eficaz.

\section{Palabras clave}

Discriminación racial o étnica, derecho antidiscriminatorio, formas de discriminación, jurisprudencia TEDH y TJUE, organismos para la igualdad.

\footnotetext{
* Catedrática de Filosofía del Derecho y Política, Universitat de València. Presidenta del Consejo para la Eliminación de la Discriminación Racial o Étnica (Dirección General para la Igualdad de Trato y Diversidad, Secretaría de Estado de Igualdad, Ministerio de la Presidencia, Relaciones con las Cortes e Igualdad).

Este artículo ha sido realizado en el marco del proyecto I+D+I DER2015-65840-R (MICINN/FEDER) «Diversidad y Convivencia: los derechos humanos como guía de acción», del Ministerio de Ciencia, Innovación y Universidades y el Fondo Europeo de Desarrollo Regional.
} 


\begin{abstract}
In recent decades there has been a significant development of European and international legal instruments related to prohibiting racial and ethnic discrimination. Nevertheless, this regulatory framework needs further improvement and implementation so that it can also combat new forms of discrimination. Along these lines, this article critically reviews international and European laws on discrimination and sets out the current state of the question. Based on this analysis, it proposes strengthening legal standards to reinforce protective measures against discrimination and enhancing the role of specialised bodies to foster equality, with the end purpose of fighting against racial and ethnic discrimination more effectively and efficiently.
\end{abstract}

\title{
Keywords
}

Racial and ethnic discrimination, anti-discrimination laws, forms of discrimination, ECHR and ECJ jurisprudence, equality bodies.

\begin{abstract}
SUMARIO. 1. Introducción. 2. Del marco jurídico internacional al europeo. 2.1. La Convención Internacional sobre la Eliminación de Todas las Formas de Discriminación Racial. 2.2. El Convenio Europeo de Derechos Humanos y el derecho antidiscriminatorio en la Unión Europea. 3. Viejas y nuevas formas de discriminación racial o étnica. 3.1. La diferencia vinculada a la extranjería. 3.2. La amenaza del populismo nacionalista. 4. Protección frente a la discriminación. 4.1. La importancia de la jurisprudencia del TEDH y el TJUE. 4.2. Los organismos especializados para la protección de la igualdad y la no discriminación. 5. A modo de conclusión.
\end{abstract}

\section{Introducción}

El concepto discriminación racial o étnica hace referencia a toda distinción, exclusión, restricción o preferencia por razón de raza u origen étnico que anula o menoscaba el reconocimiento, goce o ejercicio, en condiciones de igualdad, de los derechos humanos y libertades fundamentales en las esferas política, económica, social, cultural o en cualquier otra esfera de la vida pública. Así veremos que lo reconocen diferentes instrumentos internacionales que han inspirado las disposiciones de los sistemas regionales y nacionales en la protección del principio de igualdad y la lucha contra la discriminación.

La proliferación de normas destinadas a prohibir la discriminación no ha conseguido disminuir lo suficiente esos actos en los que, en palabras de Dworkin (1985, p. 66), no hay una «justificación libre de prejuicios» que es precisamente lo que hace que sean discriminatorios, ni tampoco aquellas otras formas de trato diferencial que no se basan necesariamente en un prejuicio sino en el hecho de no tomar en cuenta las especificidades de un determinado grupo como ocurre en los casos de discriminación indirecta.

Aunque la palabra raza no identifica ninguna realidad biológica y existen evidencias científicas de que las doctrinas de superioridad racial son científicamente falsas, moralmente condenables, socialmente injustas y peligrosas por lo que deben rechazarse, lo cierto es que sigue habiendo racismo. Es decir, aunque pueda considerarse superado el racismo de base biologicista y esencialista, siguen existiendo víctimas del racismo, la discriminación racial, la xenofobia y las formas 
conexas de intolerancia, incluidas sus formas y manifestaciones contemporáneas ${ }^{1}$, o lo que es lo mismo, no hay razas, pero sí racistas. Como afirma Cavalli-Sforza (1997: p. 22) el concepto de raza es erróneo, por tanto, no se puede aplicar a la especie humana, en ese sentido la «variación invisible siempre es grande en cualquier grupo, ya sea el de un continente, una región, una ciudad o un pueblo, y mayor que la que existe entre continentes, regiones, ciudades o pueblos. Así pues, la pureza de la raza es inexistente, imposible y totalmente indeseable». Racista es, por tanto, quien considera que existen razas que se pueden delimitar biológicamente (atendiendo al fenotipo o al genotipo), pero también quien tiene el sentimiento de pertenecer a un «tipo» humano mejor que el de otro (de tal manera que incluso puede defender los derechos de la «raza inferior») o quien considera que existen una pluralidad de razas que son iguales.

Por eso, como apunta Kendi (2019, pp. 18-23) no basta con no ser racista, porque también ese término apela a un espacio que no es neutro, es necesario impulsar un antirracismo basado en la igualdad, que genere políticas para combatir las injusticias sociales. Ello exige entender, como veremos, que el racismo es en sí mismo institucional, estructural y sistemático. Las sociedades democráticas actuales tienen en su propio germen ideas racistas que se aceptan como naturales de tal manera que parecen incluso banales, por eso puede ser difícil entender y sobre todo poner en práctica medidas antirracistas para conseguir la igualdad. Para ello, como este estudio propone, hay que comenzar identificando las actuales formas de discriminación racial o étnica, como manifestación evidente de las políticas que generan desigualdad; analizar el marco jurídico vigente, con especial atención a los avances que se han producido en este ámbito y buscar mecanismos para perfeccionarlo en aras de conseguir una mayor protección.

Como acertadamente señala Balibar (1991, pp. 31-48) la noción de raza tiene un significativo alcance social y ha dado lugar a nuevas formas de racismo que sustituyen o complementan el trato diferencial adjudicado a la raza con la etnia, la nacionalidad o la cultura. Ello genera lo que podría considerarse un nuevo racismo que, en realidad, se asienta en los mismos postulados que el tradicional, pero busca nuevas formas de expresión. La discriminación racial o étnica puede entenderse como una de esas manifestaciones de lo que se considera un nuevo racismo y supone que determinadas personas y grupos sufrirán las consecuencias de esa restricción por motivos raciales, étnicos, nacionales, religiosos o culturales, e incluso en algunas ocasiones de varios o todos estos factores juntos que exigirán una lectura múltiple e interseccional. La proliferación de casos de discriminación por los mencionados motivos se debe, también en buena medida, a los actuales escenarios en los que las perspectivas y los recorridos vitales de las personas vienen dominados por la incertidumbre y la sensación de riesgo a la que ya aludía Beck (2006, pp. 114-115); el tránsito de una sociedad explicada a partir de ejes de desigualdad verticales (arribaabajo) y materiales, a una sociedad en la que se hacen más frágiles o se rompen los vínculos de integración social (dentro-fuera); y el paso de una sociedad de clases a una sociedad atravesada por múltiples ejes de desigualdad y de diversificación social (Subirats, 2010, p. 23).

El desarrollo de los instrumentos jurídicos internacionales y europeos relativos a la prohibición de la discriminación racial o étnica ha sido significativo en las últimas

\footnotetext{
1 Naciones Unidas, Asamblea General, Resolución aprobada por la Asamblea General el 22 de diciembre de 2018, Llamamiento mundial para la adopción de medidas concretas para la eliminación total del racismo, la discriminación racial, la xenofobia y las formas conexas de intolerancia y para la aplicación y el seguimiento generales de la Declaración y el Programa de Acción de Durban, A/RES/73/262, de 15 de enero de 2019.
} 
décadas y ha supuesto un avance, nada desdeñable, en la consolidación de la prohibición de discriminación y la prevalencia del principio de igualdad. Sin embargo, dicho marco regulatorio necesita un mayor perfeccionamiento e implementación que permita también combatir las nuevas formas de discriminación. En esa línea, este trabajo realiza una revisión crítica de la principal normativa internacional y europea sobre la materia y establece el estado actual de la cuestión. Desde ese análisis, para consolidar los instrumentos de protección del derecho antidiscriminatorio, se propone por una parte, fortalecer los estándares jurisprudenciales especialmente desde la jurisprudencia del Tribunal Europeo de Derechos Humanos (TEDH), con alguna referencia a la del Tribunal de Justicia de la Unión Europea (TJUE); y por otra, desarrollar la función de los organismos especializados para la promoción de la igualdad, con la finalidad de conseguir afianzar dicha igualdad como valor, principio y derecho.

\section{Del marco jurídico internacional al europeo}

Los diferentes instrumentos que configuran el derecho internacional de los derechos humanos parten de la posibilidad de atribuir su titularidad a todo ser humano sin discriminación. La Declaración Universal de Derechos Humanos, prohíbe realizar distinción atendiendo a motivos como la raza, sin mencionar expresamente la discriminación, y sirve como base para que otras disposiciones codifiquen y consagren los principios de igualdad y no discriminación, entre ellas, los Pactos de las Naciones Unidas de 1966 sobre los Derechos Civiles y Políticos y sobre los Derechos Económicos, Sociales y Culturales, y la Convención Internacional sobre la Eliminación de todas las formas de Discriminación contra la mujer de 1979 (CEDAW) 2 . Así lo han reiterado también el Comité de Derechos Humanos, el Comité de Derechos Económicos, Sociales y Culturales, y el Comité de la CEDAW, insistiendo en que los derechos reconocidos en los mencionados Pactos deben garantizarse a todas las personas, incluidos los no ciudadanos y las personas pertenecientes a minorías raciales y étnicas ${ }^{3}$.

2.1. La Convención Internacional sobre la Eliminación de Todas las Formas de Discriminación Racial

En el marco de Naciones Unidas, la Convención Internacional sobre la Eliminación de Todas las Formas de Discriminación Racial (ICERD) constituye el marco de referencia específico sobre este tipo de discriminación ${ }^{4}$. La discriminación racial se define en el artículo 1.1 de la ICERD ${ }^{5}$ recogiendo diferentes aspectos que se asocian al racismo

\footnotetext{
2 Puede verse un panorama general de los instrumentos internacionales de derechos humanos en los que se prohíbe específicamente la discriminación contra determinados grupos en Naciones Unidas, Asamblea General, Informe del Relator Especial sobre las formas contemporáneas de racismo, discriminación racial, xenofobia y formas conexas de intolerancia, que se centra en el fenómeno de la xenofobia y su conceptualización, tendencias y manifestaciones, A/HRC/32/50, de13 de mayo de 2016, párrs. 10 a 14. En el informe también se presenta una visión introductoria a los instrumentos que recogen la prohibición de la discriminación racial en el plano regional, párrs. 15 a 25.

${ }^{3}$ Vid., por ejemplo, Comité de Derechos Humanos, Observación General n 15 (1986), sobre la situación de los extranjeros con arreglo al Pacto, párrs. 1 y 2; Comité de Derechos Económicos, Sociales y Culturales, Observación General n 20 (2009), sobre la no discriminación en los derechos económicos, sociales y culturales, párrs. 24 y 30.

${ }^{4}$ Convención Internacional sobre la Eliminación de todas las Formas de Discriminación Racial, adoptada y abierta a la firma y ratificación por la Asamblea General en su resolución 2106 A (XX), de 21 de diciembre de 1965, entró en vigor el 4 de enero de 1969, de conformidad con el artículo 19.

${ }^{5}$ Artículo 1.1 de la ICERD: «Toda distinción, exclusión, restricción o preferencia basada en motivos de raza, color, linaje u origen nacional o étnico que tenga por objeto o por resultado anular o menoscabar el
} 
y mencionando expresamente los términos de «raza» y "origen étnico» así como otros como "color» que deben interpretarse a la luz de la actualización llevada a cabo, por ejemplo, por la Conferencia de $\operatorname{Durban}^{6}$ que asimila dicho término al de afrodescendientes.

En esta referencia que hace la ICERD a la discriminación racial conviene llamar la atención sobre dos aspectos relevantes. En primer lugar, hay motivos que no aparecen específicamente mencionados, entre ellos por ejemplo la discriminación por motivos religiosos. Sin embargo, en este como en otros puntos para interpretar y aplicar de forma más actualizada la Convención es posible acudir a las recomendaciones del Comité para la Eliminación de la Discriminación Racial (CERD). Este organismo, en este supuesto en concreto, ha considerado que la Convención puede aplicarse en los casos en que la discriminación por motivos religiosos coincida con otras formas de discriminación específicamente prohibidas en virtud del mencionado artículo $1.1^{7}$.

Esta lectura extensiva, que no se ciñe a la literalidad del texto internacional, conecta, con un enfoque de la discriminación basado en la interseccionalidad. En efecto, dicho concepto, a los efectos que ahora interesan, puede ser entendido como propone Rey (2008, pp. 263-264), como una forma de discriminación en la que se combinan diversos factores al mismo tipo (en ese sentido podría denominarse múltiple, interseccional, combinada o compuesta) de tal manera, y esto es lo relevante, que la confluencia simultánea de motivos de discriminación hace que surja una nueva forma de opresión que tiene perfiles propios. No estamos, por tanto, ante la acumulación de motivos de discriminación sino ante la intersección entre ellos que genera una discriminación diferente a la mera suma.

En ese sentido, como afirma Lousada (2017, p. 33) la idea de interseccionalidad, puesto que basa la apreciación de la desigualdad en la identificación de los prejuicios derivados de la concurrencia de dos o más causas de discriminación (y no en la comparación de situaciones), permite ir más allá de una concepción de la igualdad de trato fundada en un test de comparación, para proponer una concepción de la igualdad de trato basada en un test de perjuicio, que si se utiliza de modo adecuado puede permitir mejorar la aplicación práctica de la igualdad de trato. Ciertamente esa perspectiva interseccional de la discriminación obliga, como apunta Barrère (2010, p. 251) a una revisión del derecho antidiscriminatorio clásico para superar la mera yuxtaposición de los factores de discriminación que por acumulación dan un resultado que no recoge la originalidad que la intersección supone.

En segundo lugar, la prohibición de la discriminación racial en el derecho internacional de los derechos humanos, en concreto en la ICERD no se ciñe únicamente a una visión formal de la igualdad o a una mera igualdad material ante la ley. La igualdad en el marco internacional de derechos humanos tiene carácter

reconocimiento, goce o ejercicio, en condiciones de igualdad, de los derechos humanos y libertades fundamentales en las esferas política, económica, social, cultural o en cualquier otra esfera de la vida pública».

${ }_{6}$ Conferencia Mundial contra el Racismo, la Discriminación, la Xenofobia y las Formas Conexas de Intolerancia, Durban (Sudáfrica), del 31 de agosto al 8 de septiembre de 2001. Vid. CERD, Debate temático sobre la discriminación racial de los afrodescendientes, CERD/C/SR.2081, de 9 de enero de 2012.

${ }^{7}$ Vid. CERD, Recomendación General $n^{\circ} 32$, sobre el significado y alcance de las medidas especiales en la Convención Internacional sobre la Eliminación de todas las Formas de Discriminación Racial, CERD/C/GC/32, de 29 de septiembre de 2009, párr. 7; y P. S. N. c. Dinamarca (CERD/C/71/D/36/2006), párr. 6.3. 
sustantivo, de tal manera que obliga a los Estados a adoptar medidas para luchar contra la discriminación racial deliberada o intencional, así como contra la discriminación racial no intencional o de facto ${ }^{8}$.

Este amplio abanico condiciona no solo la aprobación de disposiciones en el ámbito del derecho antidiscriminatorio sino la implementación y efectividad de las mismas y permite ir adaptando la interpretación de la Convención a la realidad. En ese sentido, por ejemplo, el CERD en la recomendación general $n^{\circ} 35$ se ocupa de la lucha contra el discurso de odio racista ${ }^{9}$, aunque este no se recoja expresamente en la Convención señalando, como exigencia mínima y sin perjuicio de otras medidas, que es indispensable para combatir dicho discurso una legislación completa contra la discriminación racial, tanto en derecho civil y administrativo como en derecho penal.

Además, el CERD ha corroborado esa lectura no condicionada por los aspectos expresamente recogidos en la Convención, al señalar en su recomendación general $n^{\circ} 32$ acerca del significado y alcance de las medidas especiales en la Convención, que la prohibición de la discriminación racial en el marco de la ICERD no puede interpretarse de manera restrictiva, ya que, se pretende alcanzar la igualdad sustantiva (de facto) en el goce y el ejercicio de los derechos humanos. Por ello, El Comité insiste en que la Convención se aplica tanto a la discriminación deliberada o intencional como a la discriminación en la práctica ${ }^{10} \mathrm{y}$ a la discriminación estructural ${ }^{11}$.

Precisamente la dimensión práctica de la discriminación exige la ampliación de los motivos de la misma desde la noción que el Comité denomina de «interrelación», que permite abordar situaciones de discriminación doble o múltiple, o lo que es lo mismo introducir la idea de interseccionalidad, cuando se conectan uno o varios de los motivos enumerados en el citado artículo 1 de la Convención. Se considera por tanto discriminación la intencional y la práctica que incluye no solo una «distinción, exclusión o restricción» injustificables sino también una «preferencia» injustificable, lo que hace especialmente importante que los Estados partes distingan entre las «medidas especiales» y dichas preferencias injustificables ${ }^{12}$.

Esta sutil distinción que va de las medidas especiales a las preferencias injustificables, se relaciona con lo establecido en el artículo 1.2 ICERD cuando señala que la Convención no será de aplicación en el caso de las distinciones, exclusiones, restricciones o preferencias que haga un Estado parte entre los ciudadanos y los no ciudadanos. Es fundamental conjugar esta previsión, que permite la diferenciación en el ámbito de la extranjería, con el mencionado enfoque sustantivo y no formalista de la igualdad en la línea de lo señalado en los instrumentos de derecho internacional de los derechos humanos, ya que, resulta aplicable en el contexto de las leyes y políticas relativas a la ciudadanía, la nacionalidad y la inmigración. En ese sentido, la Relatora

\footnotetext{
8 Naciones Unidas, Asamblea General, Informe de la Relatora Especial sobre las formas contemporáneas de racismo, discriminación racial, xenofobia y formas conexas de intolerancia, para la aplicación y seguimiento generales de la Declaración y el Programa de Acción de Durban, preparado de conformidad con la resolución 72/157 de la Asamblea General, que analiza la amenaza que supone el populismo nacionalista para los principios fundamentales de los derechos humanos de no discriminación e igualdad, A/73/305, de 6 de agosto de 2018.

${ }^{9}$ CERD, Recomendación General n 35 sobre la lucha contra el discurso racista, CERD/C/GG/35, de 26 de septiembre de 2013, párr. 9.

${ }^{10}$ CERD, Recomendación general $\mathrm{n}^{\circ} 32$ sobre el significado y alcance de las medidas especiales en la Convención Internacional sobre la eliminación de todas las formas de discriminación racial, CERD/C/GC/32, de 29 de septiembre de 2009, párr. 6.

11 CERD, Recomendación general $\mathrm{n}^{\circ} 34$ sobre la discriminación contra afrodescendientes, CERD/C/GC/34, de 3 de octubre de 2011.

${ }^{12}$ CERD, Recomendación general n 32, op. cit., párrs. 6 y 7.
} 
Especial ${ }^{13}$ insiste en que debe interpretarse de manera restrictiva y de conformidad con el mencionado derecho internacional de los derechos humanos y las normas relativas a la prohibición de la discriminación y a la igualdad ante la ley, la precisión del artículo 1.2 ICERD, relacionado con el 1.3 ICERD que tampoco permite que la Convención afecte a las disposiciones legales de los Estados sobre nacionalidad, ciudadanía y naturalización. Es decir, las legislaciones nacionales en el ámbito de la extranjería, aún con las salvedades señaladas, no pueden aplicarse de una forma que resulten racialmente discriminatorias o como pretexto para la discriminación racial.

La recomendación general $n^{\circ} 30$ del CERD avala esa interpretación sobre la aplicación del artículo 1.2 ICERD al considerar que no se debe socavar la igualdad y la no discriminación consagradas en el artículo 5 de la Convención y en otros instrumentos jurídicos internacionales. Por tanto, es posible que existan criterios de diferenciación basados en la ciudadanía o la situación migratoria, tal como de hecho ocurre en las legislaciones de extranjería de los Estados parte que crean estatutos jurídicos específicos, pero a tenor de esta recomendación dicha distinción se considerará constitutiva de discriminación si los criterios para establecer esa diferencia, de acuerdo con los objetivos y propósitos de la Convención, no se aplican para alcanzar un objetivo legítimo o no están proporcionados con el logro de ese objetivo. Por eso, los Estados, por una parte, tienen la obligación de que su legislación sobre la prohibición de la discriminación racial se aplique a los no ciudadanos, con independencia de su situación; $y$, por otra parte, deben asegurarse de que sus normativas nacionales no tengan ningún efecto discriminatorio sobre los extranjeros. Además, esa protección se ha de complementar con la adopción de medidas concretas en relación al disfrute de los derechos económicos, sociales y culturales, el discurso de odio y la violencia racial, el acceso a la ciudadanía, la administración de justicia, y las expulsiones ${ }^{14}$.

Con todo, tras cincuenta años de vigencia de la Convención, y con el significativo papel interpretativo que desempeña el CERD, como se analizará a propósito de las nuevas formas de discriminación racial o étnica, los criterios de diferenciación injustificada respecto a los extranjeros y su conjunción con teorías supremacistas vinculadas a los discursos del populismo nacionalista que afectan a distintas minorías, siguen siendo dos de las grandes amenazas para la garantía del principio de igualdad que socavan las oportunidades que ofrece la lectura extensiva en su dimensión garantista de la Convención.

\subsection{El Convenio Europeo de Derechos Humanos y el derecho antidiscriminatorio en la Unión Europea}

El Convenio para la protección de los Derechos Humanos y de las Libertades Fundamentales (CEDH), aprobado en Roma el 4 de noviembre de 1950, recoge en su artículo 14 la prohibición de discriminación por determinadas causas (sexo, raza, color, lengua, religión, opiniones políticas u otras, origen nacional o social, pertenencia a una minoría nacional, fortuna, nacimiento o cualquier otra situación) en relación a los derechos y libertades reconocidos en el Convenio. Con dicha regulación, el artículo $14 \mathrm{CEDH}$ ha sido visto como una forma de interpretar el

\footnotetext{
${ }^{13}$ Naciones Unidas, Asamblea General, Consejo de Derechos Humanos, Informe de la Relatora Especial sobre las formas contemporáneas de racismo, discriminación racial, xenofobia y formas conexas de intolerancia, sobre la cuestión de la discriminación racial en el contexto de las leyes, las políticas y las prácticas relativas a la ciudadanía, la nacionalidad y la inmigración, A/HRC/38/52, de 25 de abril de 2018, párr. 19.

${ }^{14}$ CERD, Recomendación General n 30 sobre discriminación contra los no ciudadanos, CERD/C/GC/34, de 5 de octubre de 2004.
} 
conjunto de las disposiciones del convenio, pero no como un artículo autónomo, no enuncia una prohibición independiente relativa a la discriminación (Gil, 2017, p. 919). Esta ha sido una de las críticas reiteradas a dicha disposición, lo cual no significa que no esté dotada de utilidad, pero sí que para que conseguir su plena eficacia ha tenido que ser completada.

El Protocolo $\mathrm{n}^{\circ} 12$ del Convenio, hecho en Roma el 4 de noviembre de 2000 y que entró en vigor el 1 de abril de 2005, intenta corregir las restricciones del artículo 14 CEDH y amplía la prohibición general de discriminación a todos los derechos fundamentales y ordinarios, más allá de los que se reconocen de forma expresa en el Convenio y sus Protocolos. De esta manera, se amplía el ámbito de aplicación del artículo $14 \mathrm{CEDH}$, ya que deja de ser necesario el invocar la vulneración de algún derecho del Convenio o sus Protocolos, y puede acudirse independientemente al derecho a la no discriminación (Casado, 2012, p. 61). Con todo, el Protocolo no modifica los motivos a los que se refiere el artículo $14 \mathrm{CEDH}$, desaprovechando la posibilidad de introducir alguno nuevo como, por ejemplo, el de discapacidad.

En la memoria explicativa al Protocolo $\mathrm{n}^{\circ} 12$ se reconoce expresamente que la protección ofrecida por el artículo $14 \mathrm{CEDH}$ por lo que se refiere a la igualdad y a la no discriminación es limitada, especialmente si se compara con la que se contempla en las disposiciones de otros instrumentos internacionales, lo cual en buena medida se relaciona con su poca relevancia tradicionalmente en la jurisprudencia del TEDH a propósito de la discriminación racial, aunque como se analizará más adelante esta va progresivamente en aumento. Además, en dicha memoria se concreta que el alcance de la protección adicional, en virtud del artículo 1, se refiere a los casos en que una persona es objeto de discriminación: en el goce de todo derecho concedido al individuo por el derecho nacional; respecto a cualquier derecho derivado de obligaciones de las autoridades públicas en el derecho nacional; por parte de las autoridades públicas debido al ejercicio de un poder discrecional; y en otros actos $u$ omisiones por parte de las autoridades públicas ${ }^{15}$.

Estas disposiciones a las que ha recurrido el TEDH permiten asegurar el principio de igualdad y la cláusula de no discriminación a nivel jurisprudencial y también desde organismos de supervisión como la Comisión Europea contra el Racismo y la Intolerancia (ECRI). Como parte de su trabajo de monitoreo de cada país, la ECRI analiza la situación en cada uno de los Estados miembros y hace recomendaciones para abordar los problemas de racismo e intolerancia que identifica. Entre dichas recomendaciones la $n^{0} 7^{16}$ recoge expresamente la definición de racismo, así como la discriminación racial directa e indirecta, atendiendo a motivos como la raza, el color, el idioma, la religión, la nacionalidad, el origen nacional o étnico en la línea de lo establecido en la ICERD.

En cuanto al ámbito comunitario la igualdad de trato y no discriminación constituye uno de los principios básicos de la Unión Europea y ha dado lugar al desarrollo significativo de disposiciones de derecho antidiscriminatorio. El artículo 2 del Tratado de la Unión Europea hace referencia a la no discriminación como un valor fundamental y a la lucha contra la discriminación como uno de sus objetivos. Además, el artículo 19 (antiguo artículo 13) del Tratado de Funcionamiento de la Unión Europea, habilitó al Consejo para «adoptar acciones adecuadas para luchar contra la

\footnotetext{
15 Instrumento de ratificación del Protocolo $n^{\circ} 12$ al Convenio para la Protección de los Derechos Humanos y de las Libertades Fundamentales (número 177 del Consejo de Europa), hecho en Roma el 4 de noviembre de 2000, BOE n 64, de 14 de marzo de 2008, pp. 15299 a 15304.

${ }^{16}$ ECRI, Recomendación n ${ }^{\circ} 7$ de Política General de la ECRI sobre legislación nacional para combatir el racismo y la discriminación racial, (2003) 8, aprobada el 13 de diciembre de 2002, apartados 1 (b) y (c). Enmendada 2017.
} 
discriminación por motivos de sexo, de origen racial o étnico, religión o convicciones, discapacidad, edad u orientación sexual». En la misma línea la Carta de los Derechos Fundamentales de la Unión Europea en su artículo 21 prohíbe toda discriminación en base a los motivos que enuncia y recoge el derecho a la diversidad (artículo 22), la igualdad entre hombres y mujeres (artículo 23) y el derecho a la integración de las personas con discapacidad (artículo 26).

Desde esta fundamentación normativa, la Directiva 2000/43/CE, relativa a la aplicación del principio de igualdad de trato de las personas independientemente de su origen racial o étnico constituye el instrumento más importante en la lucha contra este tipo de discriminación ${ }^{17}$. Resulta asimismo relevante en este contexto la Decisión marco 2008/913/JAI del Consejo, de 28 de noviembre de 2008, relativa a la lucha contra determinadas formas y manifestaciones de racismo y xenofobia mediante el Derecho penal, que tiene como objetivo la aproximación de las disposiciones legales y reglamentarias de los países de la UE referentes a los delitos de carácter racista o xenófobo.

Desde diciembre de 2009, con la entrada en vigor del Tratado de Lisboa, que concede a la Carta de Derechos Fundamentales de la Unión Europea la misma validez jurídica que los tratados de la Unión Europea, se ha seguido reforzado la normativa encaminada a combatir la discriminación por los diferentes motivos que concreta el artículo 21. Así, por ejemplo, para la protección de las víctimas de discriminación es destacable la aprobación de la Directiva 2012/29/UE ${ }^{18}$ en la que se concretan normas mínimas sobre los derechos, el apoyo y la protección de las víctimas de delitos, y se reconoce expresamente la especial atención que debe prestarse a las víctimas afectadas por un delito motivado por prejuicios o por motivos de discriminación, relacionado con sus características personales.

La Directiva 2000/43/CE fue transpuesta por los Estados de diferentes maneras bien reproduciendo los propios términos de la directiva, como en el caso de Italia, Grecia y Chipre; bien adoptando una normativa que va más allá de lo exigido por la propia Directiva, como en Austria, Bélgica, Finlandia, Irlanda, Hungría y Países Bajos; o bien combinando la normativa sobre múltiples ámbitos discriminatorios con aquella que los aborda por separado, como es el caso de Dinamarca, Países Bajos y Suecia (Cormack and Bell, 2005, p. 13).

En España, no se aprovechó plenamente la oportunidad que la transposición de esta Directiva ofrecía, no se le prestó demasiada atención parlamentaria instando un debate que hubiera sido necesario, ni se consultaron a los agentes sociales

\footnotetext{
17 Directiva 2000/43/CE, de 29 de julio de 2000, relativa a la aplicación del principio de igualdad de trato entre las personas independientemente de su origen racial o étnico. Junto a ella otras directivas configuran el corpus jurídico en relación al principio de igualdad, entre ellas: la Directiva 2000/78/CE, de 27 de noviembre de 2000, relativa al establecimiento de un marco general para la igualdad de trato en el empleo y la ocupación; la Directiva 2004/113/CE, de 13 de diciembre de 2004, sobre aplicación del principio de igualdad de trato entre hombres y mujeres en el acceso a bienes y servicios y su suministro; la Directiva 2006/54, de 5 de julio de 2006, relativa a la aplicación del principio de igualdad de oportunidades e igualdad de trato entre hombres y mujeres en asuntos de empleo y ocupación; Directiva 2010/18, de 8 de marzo de 2010, por la que se aplica el Acuerdo marco revisado sobre el permiso parental; y la Directiva 2010/41, de 7 de julio de 2010, sobre la aplicación del principio de igualdad de trato entre hombres y mujeres que ejercen una actividad autónoma.

18 Directiva 2012/29, de 25 de octubre de 2012, por la que se establecen normas mínimas sobre los derechos, el apoyo y la protección de las víctimas de delitos. Junto a ella otras disposiciones son reseñables en la lucha contra la discriminación: Directiva 2011/36, de 5 abril de 2011, relativa a la prevención y lucha contra la trata de seres humanos y a la protección de las víctimas; y Directiva 2011/99, de 13 de diciembre de 2011, sobre la orden europea de protección, reforzada por el Reglamento (UE) $n^{\circ}$ 606/2013, de 12 de junio de 2013, relativo al reconocimiento mutuo de medidas de protección en materia civil, que garantiza el reconocimiento de dichas medidas en toda la Unión.
} 
(Cachón, 2004). Desde un punto de vista formal, la Ley $62 / 2003^{19}$ realizó la transposición de la Directiva 2000/43/CE, pero desde una perspectiva de mínimos. Se incorporaron las definiciones de discriminación, directa, indirecta y de acoso incluidas en la directiva de igualdad racial e igualdad en el empleo, señalando la posibilidad de adoptar medidas específicas a favor de ciertos colectivos destinados a prevenir o compensar sus desventajas para alcanzar la plena igualdad por razón de su origen racial o étnico. Para ello es necesario respetar el principio de proporcionalidad y el hecho de que los sujetos beneficiarios formen parte de un grupo históricamente discriminado.

En el ámbito de aplicación personal, la Directiva excluye expresamente su aplicación en relación a las diferencias de trato por motivos de nacionalidad, siendo así respetuosa con las respectivas normativas nacionales al respecto. En esa línea, la legislación española de transposición incluye la misma cláusula de exclusión mencionada en la directiva europea, así mismo en la Disposición Adicional séptima de la Ley 62/2003 se indica que tales medidas antidiscriminatorias no afectan a la normativa de los extranjeros en España. En dicho ámbito procederá la aplicación de la Ley Orgánica 4/2000 de derechos y libertades de los extranjeros en España y su integración social (LOEX) con sus correspondientes reformas y su reglamento de desarrollo ${ }^{20}$. Así, los artículos 23 y 24 de la LOEX contemplan el derecho a la igualdad estableciendo lo que se consideran actos discriminatorios y la aplicabilidad del procedimiento sumario para la tutela judicial contra cualquier práctica discriminatoria que comporte vulneración de derechos y libertades fundamentales (artículo 53.2 de la Constitución). De esta manera, se consagra el principio de igualdad entre extranjeros y españoles, con las excepciones legalmente previstas, lo cual es llamativo ya que, como se analizará, una parte importante de las víctimas de discriminación racial son los nacionales de terceros países (Esteve, 2013, pp. 29-31).

Por otra parte, la Directiva 2000/43 establece la necesidad de que los Estados miembros constituyan organismos de promoción de la igualdad de trato entre todas las personas sin discriminación por motivo de su origen racial o étnico para, entre otras, realizar funciones de asistencia independiente a las víctimas de discriminación, estudios independientes y presentar informes formulando recomendaciones. De esta manera la discriminación racial o étnica adquiere un papel protagonista con un mecanismo propio de protección (Schiek, 2002, pp. 290-291).

\section{Viejas y nuevas formas de discriminación racial o étnica}

Como se ha señalado a la luz del marco jurídico internacional y europeo no cabe acudir a la raza o la etnia como motivo de diferenciación ni tampoco a la nacionalidad.

\footnotetext{
${ }^{19}$ Ley $62 / 2003$, de 30 de diciembre, de medidas fiscales, administrativas y del orden social, BOE $n^{\circ} 313$, de 31 de diciembre de 2003.

${ }^{20}$ Ley Orgánica 4/2000, de 11 de enero, sobre derechos y libertades de los extranjeros en España y su integración social, incluyendo las modificaciones introducidas por la ley orgánica 8/2000, de 22 de diciembre (BOE $n^{\circ} 307$, de 23 de diciembre, corrección de errores en BOE $n^{\circ} 47$, de 23 de febrero de 2001); por la Ley Orgánica 11/2003, de 29 de septiembre (BOE $n^{\circ} 234$, de 30 de septiembre); por la Ley Orgánica 14/2003, de 20 de noviembre (BOE n² 279, de 21 de noviembre); por la Ley Orgánica 2/2009, de 11 de diciembre (BOE $n^{\circ}$ 299, de 12 de diciembre); por la Ley Orgánica 10/2011, de 27 de julio (BOE $n^{\circ}$ 180, de 28 de julio); por el Real Decreto-ley 16/2012, de 20 de abril (BOE n 98, de 24 de abril); por la sentencia 17/2013, de 31 de enero, del Tribunal Constitucional (BOE $n^{\circ} 49$, de 26 de febrero); por la Ley Orgánica 4/2013, de 28 de junio (BOE n 155, de 29 de junio); por la Ley Orgánica 4/2015, de 30 de marzo (BOE $n^{\circ} 77$, de 31 de marzo), por la sentencia del Tribunal Supremo de 10 de febrero de 2015 (BOE $n^{\circ} 119$, de 19 de mayo); por la Ley Orgánica 8/2015, de 22 de julio (BOE $n^{\circ} 175$, de 22 de julio) y por el Real Decreto-ley 11/2018, de 31 de agosto (BOE n² 214, de 4 de septiembre).
} 
Sin embargo, la excepción vinculada a la extranjería, difícil de compatibilizar con la prohibición de discriminación, ha sido tradicionalmente, y sigue siendo en múltiples formas, un escenario de continuas discriminaciones que tensionan el objetivo de la igualdad racial sustancial.

\subsection{La diferencia vinculada a la extranjería}

En la base de los actuales movimientos antinmigración, que se definen por considerar al extranjero como una permanente amenaza, persiste, en primer lugar, la raíz del tradicional racismo que quería considerarse superado en Europa. La diferencia vinculada a la extranjería que se traslada al ámbito normativo es difícilmente compatible con la prohibición de discriminación. Como advierte Bobbio (2010, pp. 211-212) ese racismo no parte solo de considerar al otro como diferente, sino que por tal hecho se le visibiliza como inferior y, por tanto, objeto de dominio. El racismo no conlleva únicamente el considerar que existe una pluralidad de razas, aún sabiendo que es falso, sino que se establece su jerarquía de tal forma que existen razas superiores e inferiores, así surge la pretensión de dominar en quien se cree superior. En esa relación el superior se atribuye el deber de ayudar al inferior, mejorarlo, como forma de redimirlo de su inferioridad. En el contexto democrático, de acuerdo con las disposiciones internacionales de derecho antidiscriminatorio, encontrar respuestas equitativas exige superar prejuicios que impiden, como el mencionado autor apunta considerar que todo ser humano sea igual al otro $\mathrm{y}$, a la vez, que todo ser humano sea diferente al otro.

Junto a ese racismo más detectable prolifera también, al arrimo de los movimientos antiinmigración, la xenofobia. Uno de los ejes básicos del discurso xenófobo es la defensa de la identidad nacional y cultural vinculada ahora además al nacionalismo y al euroescepticismo. Se trata de una xenofobia que siempre ha estado latente en las políticas de inmigración de la Unión Europea, como se evidencia claramente en el acceso al mercado de trabajo y en el disfrute de otros derechos, basada en un discurso de la prioridad de los nacionales y los europeos. La aceptación de posturas xenófobas se relaciona con el manifiesto rechazo al racismo y el hecho de que ese odio al extranjero, en ocasiones, sea más disimulado y sutil.

Ese mensaje de repulsa al extranjero conecta con el tercer elemento del que se aprovechan los movimientos antiinmigración para invisibilizar a los inmigrantes en su diversidad, ahondando en todos los estereotipos, mitos y fobotipos vinculados a la movilidad humana. Esta idea es tan simple, ante situaciones extremadamente complejas, que se difunde rápidamente y entonces proliferan las soluciones fáciles, dicotómicas y falaces que reconducen al lema persistente de «nosotros o los otros». Como recuerda Tejada (2013, p. 13) la manipulación que se realiza de los sentimientos de indignación y temor que los ciudadanos sienten ante una situación de crisis económica y social, facilita la aceptación de estas propuestas populistas, que no siempre se identifican como posturas extremistas, racistas y radicales, sino que en ocasiones surgen como una reacción de defensa y lucha ante los abusos o la ineficacia (Cea D'Ancona, 2015). En ese sentido, como apunta la Relatora Especial sobre las formas contemporáneas de racismo, discriminación racial, xenofobia y formas conexas de intolerancia en el informe sobre la cuestión de la discriminación racial en el contexto de las leyes, las políticas y las prácticas relativas a la ciudadanía, la nacionalidad y la inmigración ${ }^{21}$, persisten dos argumentos recurrentes que se vinculan a la extranjería y son utilizados para justificar tratos diferenciales que

\footnotetext{
${ }^{21}$ Naciones Unidas, Asamblea General, A/HRC/38/52, op. cit., párrs. 60 a 65
} 
constituyen verdaderas discriminaciones por razón de la nacionalidad: por una parte, el vínculo con la crisis económica, y por otra, con la seguridad.

En cuanto a la primera cuestión, desde Naciones Unidas se ha acreditado la relación existente entre crisis económica, medidas de austeridad, mayor desigualdad y discriminación. Así, es patente «la relación directa entre el aumento de la disparidad económica y el crecimiento de los partidos populistas y xenófobos ${ }^{22}$, siendo los migrantes, los refugiados y otros no nacionales considerados, a menudo, como el chivo expiatorio al que se hace responsable de esa situación de recesión del orden neoliberal cuando en realidad, como los autóctonos, son víctimas de ella. La creencia en la idea de la competencia en el empleo que se considera que la inmigración supone, nace en buena medida de imaginarios colectivos interesadamente creados y del profundo desconocimiento del funcionamiento de los mecanismos normativos que se aplican en este ámbito. La mezcla de confusión en la información y la necesidad de buscar un chivo expiatorio en situaciones preocupantes, como la de crisis económica, han contribuido a fomentar y propagar estereotipos que son falsos.

Los discursos sobre la inmigración, vista como creciente problema no son nuevos y han servido para justificar un trato diferente a nivel jurídico que bordea muchas veces los supuestos de discriminación, así por, ejemplo el caso español es significativo en el hecho de que haya tenido que ser la jurisprudencia quién haya revisado al alza los derechos de los extranjeros considerando, en más de una ocasión, partes de la normativa como inconstitucionales (Solanes, 2018). Además, estos discursos van acompañados de rumores y tópicos (Gracia y Jiménez, 2016), vinculados al mercado laboral o a su nula voluntad de integración entre otros, y evolucionan hacia distintas formas de miedo.

Hasta tal punto se ha interiorizado ya como «normal y común» esa visión utilitarista del extranjero, que ya ni siquiera se plantea la desigualdad que a ella subyace, si no que incluso se sobredimensiona hasta el mínimo reconocimiento de derechos al extranjero si es visto como una amenaza para el autóctono. Como apunta De Lucas (2012, p. 40) la visión instrumental del extranjero refuerza la idea de que el contrato de extranjería (en cuanto estatuto jurídico o conjunto de derechos y deberes que al inmigrante le corresponde) es ajeno al contrato de ciudadanía. Esa permanencia estructural de los criterios de acceso conlleva una visión limitada de la inclusión del inmigrante que ahonda en su vulnerabilidad. Es cierto que existen múltiples formas y escalas en el reconocimiento de un estatuto jurídico a los extranjeros (relacionadas también con el tipo de residencia de larga duración o meramente temporal), pero los más acordes a los planteamientos de justicia social, pasan por un reconocimiento de derechos, claramente en el ámbito laboral (Carens, 2013, pp. 88-128).

Frente a los planteamientos que consideran a los inmigrantes como una carga económica, el Relator Especial sobre los derechos humanos enfatiza que «se ha determinado que la inmigración tiene un impacto mínimo sobre el desempleo de los residentes y un efecto positivo general en la generación de empleo y la inversión» ${ }^{23}$. En la ya mencionada Conferencia de Durban, se insiste en que las políticas relativas a la migración no deberían basarse en el racismo, la discriminación racial, la xenofobia

\footnotetext{
${ }^{22}$ Naciones Unidas, Asamblea General, Consejo de Derechos Humanos, Informe del Relator Especial sobre las formas contemporáneas de racismo, discriminación racial, xenofobia y formas conexas de intolerancia, elaborado en cumplimiento de la resolución 34/35 del Consejo de Derechos Humanos, A/HRC/35/41, de 9 de mayo de 2017, párr. 48.

${ }^{23}$ Naciones Unidas, Asamblea General, Informe del Relator Especial sobre los derechos humanos de los migrantes, presentado de conformidad con la resolución 68/179 de la Asamblea. A/69/302, de 11 de agosto de 2014, párrs. 20, 25 y 98.
} 
y las formas conexas de intolerancia (párr. 12), aunque se sigue propagando de forma estratégica, para los intereses de determinados sectores, ese relato económico inexacto sobre los no nacionales pertenecientes a determinados grupos étnicos, razas y religiones.

Por otra parte, la constante preocupación por la seguridad nacional y las amenazas terroristas, han llevado a prácticas que suponen una discriminación racial por motivos de nacionalidad o situación migratoria. Un buen ejemplo de ello son las constantes vulneraciones de derechos en las fronteras (Solanes, 2016) y muy especialmente en la frontera sur española con prácticas tan cuestionadas desde el punto de vista legal y social como las denominadas "devoluciones en caliente» (Solanes, 2017). Esa tendencia queda contrastada en las prácticas ilegales ampliamente documentadas en los informes temáticos del Relator Especial ${ }^{24}$.

En el último de ellos, el de 2018, se llama la atención sobre dos formas de discriminación conexas a este eje securitario: el límite en el acceso y disfrute de la ciudadanía y la nacionalidad; y la difusión de información falsa en la que se describe a ciertos grupos raciales, nacionales y religiosos como amenazas intrínsecas a la seguridad nacional. El recurso a argumentos vinculados a la seguridad nacional y a la lucha contra el terrorismo es constante para privar o dificultar el acceso a la ciudadanía o la nacionalidad sin que, obviamente, los Estados reconozcan que se trata expresamente de una situación de discriminación por motivos de raza u origen étnico o nacional en los procesos de privación de la ciudadanía. En ese sentido, tiene razón el mencionado informe cuando señala que ese tipo de políticas tienen un efecto desproporcionado en los grupos raciales, nacionales y religiosos marginados, es más, la discriminación racial sigue siendo un efecto previsible de una política de seguridad nacional que no se acaba de adaptar a unos objetivos legítimos ${ }^{25}$.

En las permanentes dificultades para el acceso a la ciudadanía y la nacionalidad se asiste a un proceso de consideración de las personas inmigrantes al margen de la legalidad que crea las condiciones, por ejemplo, para la racialización del trabajo y de la ciudadanía (Mezzadra y Nielson, 2014, pp. 13-14). Con el tiempo se consolidan categorías diferentes con distintos estatutos jurídicos. Así encontramos, en primer lugar, una especie de ciudadano informal, que puede residir durante largos períodos de tiempo en una comunidad, demostrando una buena conducta, potenciando una interacción con la población autóctona y que sería el beneficiario de las amnistías que le permitirían regularizar su situación, de tal manera que se estarían construyendo estrategias para legitimar determinadas formas de pertenencia informales o extraestatales. En segundo lugar, estarían los autorizados no reconocidos, fuera de la extranjería, que englobaría a los ciudadanos de pleno derecho que no son reconocidos como tales, por ejemplo, aquellos que pertenecen a una minoría y sufren discriminación por cualquier motivo (Sassen, 2010, pp. 370-374).

Las amenazas vinculadas a la seguridad se utilizan también para crear una imagen desvirtuada de determinados grupos raciales, nacionales y religiosos. Es aquí donde encuentran su encaje las prácticas policiales vinculadas al perfil racial o étnico.

\footnotetext{
${ }^{24}$ Vid. Naciones Unidas, Asamblea General, Consejo de Derechos Humanos, A/HRC/35/41, op. cit., párrs. 48 a 75; y Naciones Unidas, Asamblea General, Informe del Relator Especial sobre las formas contemporáneas de racismo, discriminación racial, xenofobia y formas conexas de intolerancia, Lucha contra el racismo, la discriminación racial, la xenofobia y las formas conexas de intolerancia y aplicación y seguimiento generales de la Declaración y el Programa de Acción de Durban, preparado de conformidad con la resolución 71/181 de la Asamblea General, A/72/287, de 4 de agosto de 2017, párrs. 11 a 45.

${ }^{25}$ Naciones Unidas, Asamblea General, Consejo de Derechos Humanos, A/HRC/38/52, op. cit., párrs. 56 a 58.
} 
Dicho perfil hace referencia al uso de generalizaciones basadas en la etnia, la raza, el origen nacional o la religión, en lugar de atender a pruebas objetivas o al comportamiento individual, para aplicar las disposiciones normativas o realizar investigaciones sobre personas que se consideran sospechosas por esos motivos (García Añón, 2013, p. 286). Este perfil supone utilizar estereotipos étnicos o raciales que dirigen, por ejemplo, los actos de las fuerzas y cuerpos de seguridad concretándose en prácticas como los chequeos de identidad desproporcionados y arbitrarios, las paradas y cacheos de miembros de grupos étnicos minoritarios y un incremento en el patrullaje en barrios de minorías étnicas (Esteve, 2019, p. 135). Como veremos este tipo de actuaciones se constatan en los casos que llegan al TEDH y el TJUE.

Por otra parte, junto a esa idea de amenaza permanente que suponen los grupos raciales o étnicos estereotipados, las estrategias de desinformación y confusión incentivan de manera expresa las preocupaciones de las poblaciones nacionales respecto a la seguridad, y contribuyen de modo determinante a estigmatizar a determinados grupos étnicos, nacionales y religiosos, haciéndolos más vulnerables a la violencia racista y xenófoba. La sensación de peligro se propaga rápidamente también, como veremos a continuación, con ideas de naturaleza etnonacionalista.

\subsection{La amenaza del populismo nacionalista}

Sin entrar en la disputa que genera el concepto de populismo ${ }^{26}$ puede abordarse la amenaza que este supone a partir de los diferentes informes de Naciones Unidas que lo vinculan al aumento de la discriminación. Conviene, en todo caso, para saber a qué se hace referencia cuando se habla de populismo, establecer unos rasgos que pueden considerarse el mínimo común denominador. Siguiendo a Vallespín y Bascuñán (2017, pp. 55-57) es posible establecer un decálogo, unos rasgos comunes que permiten identificarlo, entre ellos, los siguientes: el populismo no es una ideología sino una lógica de acción política; responde a procesos de brusco cambio social; frente a él se reacciona, mediante una descripción con tintes dramáticos, insistiendo en la necesidad de revertir la situación; apela como concepto central a la noción de pueblo; se articula a través de una polarización, como la de nosotros y los otros, buscando un antagonista; reniega de la visión pluralista de la sociedad; apela a la emocionalidad; recurre a un discurso simplificador tanto del concepto de pueblo como del de enemigo; propicia una guerra de representaciones con quienes compiten con este tipo de movimientos para explicar la realidad; y finalmente, pone en cuestión la tradicional comprensión de la democracia liberal siendo fundamental el papel que desempaña el «líder». De estos rasgos, esquemáticamente enunciados, interesa ahora, especialmente en su conexión con la discriminación, el hecho de que el populismo pueda concebirse como lógica de acción política que potencia la creación de un antagonista, es decir, que insiste en la polarización de la sociedad en el binomio schmittiano amigo-enemigo de tal manera que crea, favorece y potencia el contexto idóneo para la exclusión racial.

\footnotetext{
${ }^{26}$ No se aborda la discusión doctrinal sobre dicha noción ni los múltiples significados que el populismo puede adquirir en dimensiones geográficas diferentes siendo, por ejemplo, un movimiento de izquierda en el ámbito latinoamericano, como apunta el trabajo de Laclau y Mouffe (1987) y de derecha o extrema derecha vinculado a posiciones xenófobas en el contexto europeo, puesto que excede las posibilidades de este trabajo que se centra en la conexión entre dicho fenómeno, desde la dimensión nacionalista, y las políticas que generan desigualdad y exclusión. Sobe las diferentes variedades de populismos, en concreto, a propósito del populismo en Estados Unidos, Francia, España, Hungría, Polonia, Holanda, Dinamarca, Suiza y Austria, vid. Vallespín y Bascuñán (2017, pp. 189-258).
} 
En ese sentido el populismo supone un esfuerzo por construir comunidad a partir de diferencias y conflictos que se presentan como inconmensurables, así actúa como una lógica política que, como mantiene Laclau (2005, p. 150) «permite la institucionalización de lo social» en un juego de maniobras discursivas y ambivalencias en la que crear pueblo exige la producción discursiva de «significantes tendencialmente vacíos» (Laclau, 2009, p. 60) como se evidencia en los diferentes partidos y movimientos populistas. En ese contexto, en palabras de Mouffe (2007, pp. 57-59) la política liberal acaba siendo una mera forma de administración, una técnica de gobierno, mientras que «lo» político insiste en el mencionado antagonismo, o como lo denomina esta autora en el "agonismo» que contrapone los dos polos en las democracias contemporáneas.

En el informe de la Relatora Especial centrado en el populismo nacionalista ${ }^{27}$ se evidencia que la ascendencia de las ideologías y estrategias populistas nacionalistas supone una amenaza significativa para la igualdad racial, ya que fomenta la discriminación y la intolerancia y la creación de instituciones y estructuras que dejarán legados perdurables de exclusión racial. Desde el actual populismo nacionalista, con algunos partidos y organizaciones, se promueven prácticas y políticas excluyentes o represivas que perjudican a individuos o grupos por su raza, etnia, origen nacional y religión, en combinación con el género, la orientación sexual, la discapacidad, la condición migratoria u otras categorías sociales conexas. Además de apuntar a los extranjeros y las minorías como objetivos de sus ataques, en la actualidad estas prácticas adoptan formas especialmente virulentas y difíciles de perseguir cuando se realizan desde la opacidad que ofrecen las redes.

Como apunta Triadafilopoulos (2011, pp. 861-880) la retórica liberal no debe enmascarar lo que son, en el fondo, este tipo de movimientos excluyentes, por lo cual es imprescindible analizar cuidadosamente la fuente de las propuestas de estas políticas y sus posibles efectos, ya que, el apoyo que reciben estas ideas no se limita a los miembros de partidos y movimientos de extrema derecha. Tiene razón Kymlicka (2016, pp. 158-177) cuando señala que en esta era del populismo las propuestas multiculturales alimentan argumentos y sentimientos antiinmigrantes, incluso opiniones radicales sobre la integración cívica nacional, clasificando los deberes como una condición sine qua non de los derechos. Se evidencia así esa separación entre intereses y moralidad que tan bien ilustra Carens (2013, p. 233) al señalar que la política de asilo y refugio constituye una de esas áreas en las que la brecha entre lo que la moralidad requiere y para lo que sirve, incluso a largo plazo, es muy grande. El verdadero problema es que «la admisión de los refugiados no sirve realmente a los intereses de los ricos estados democráticos». Exactamente lo mismo ocurre a propósito de la igualdad racial o étnica, por eso, es imprescindible buscar alternativas que permitan reducir también los alicientes para emplear técnicas de exclusión, buscando «una mejor alineación de los intereses y la moralidad».

Para combatir el fenómeno del actual populismo nacionalista que puede desembocar en el discurso del odio, y también las formas novedosas que adopta en conexión, como se analizará, con el uso contemporáneo de la tecnología digital en la propagación de la intolerancia neonazi y formas conexas de intolerancia, es necesario una mínima precisión conceptual. El populismo puede considerarse como una forma de discurso o retórica, una estrategia política o un tipo de lógica política que se alinea con la exclusión. En síntesis, en sus formas más peligrosas, el populismo adopta una visión monolítica y excluyente de quién entra en la categoría de «pueblo», en la misma dinámica que se ha señalado al distinguir entre "nosotros» y los "otros», pero en su dimensión más restrictiva, y así se convierte en un potente mecanismo de

27 Vid. Naciones Unidas, Asamblea General, A/73/305, op. cit., párr. 6. 
discriminación. De ahí que para entender las peligrosas movilizaciones populistas desde la perspectiva de los derechos humanos sea fundamental tener en cuenta que tienden a ser no solo antielitistas, sino también antipluralistas, como se explica con más detalle más adelante ${ }^{28}$.

Incluso en aquellos escenarios en los que difícilmente era imaginable que encontrara cabida este tipo de discurso, por su tradición, el populismo se ha asentado. Un buen ejemplo, en el ámbito europeo, de la importancia de la ideología del populismo nacionalista con un significativo discurso antiinmigración, que ven en la diversidad cultural un problema, es el de Estados como Suecia, Dinamarca, Noruega y Finlandia. Como recuerda Ahedo (2017) Dinamarca fue uno de los primeros países en endurecer sus políticas de extranjería, llegando a uno de los mayores niveles de restricción en la Unión; Suecia ha mantenido con dificultades su tradición humanitaria y de multiculturalidad; y Noruega ha evolucionado de un modelo multicultural de inspiración sueca a seguir el esquema danés cada vez más restrictivo. El aumento de la diversidad se ha interpretado desde una perspectiva neoliberal y neonacionalista, provocando conflictos ideológicos y políticos que se han asociado a la inmigración. En estos países, ese discurso contra la inmigración, como en todo el entorno de la Unión, se ha concretado en la denominada crisis de refugiados desde 2015 en un mayor control de las fronteras y un endurecimiento en las solicitudes y las condiciones de los refugiados, lo cual ha fortalecido el discurso y desarrollo de partidos antiinmigración y populistas, ligados en buena medida a los partidos de centroderecha, y con propuestas que encajan dentro de lo que puede considerarse el neonacionalismo. Así, por ejemplo, señala Bergmann (2017) tras la fachada social liberal de los Estados nórdicos económicamente exitosos y orientados al bienestar, el populismo de derecha ha encontrado un apoyo. Los partidos que propugnan una política populista nacionalista surgieron primero en Dinamarca y Noruega en la década de 1970, y más tarde se han extendido en Suecia y Finlandia, y en Islandia a raíz de la crisis financiera de 2008. Con mayor o menor éxito, según el momento, esos movimientos populistas y nacionalistas se han ido fortaleciendo progresivamente en el contexto nórdico.

Otros Estados como Francia, Reino Unido y los Países Bajos, como apuntan Simon y Beaujeu (2018, pp. 40-41), comparten características comunes en cuanto avanzar hacia el fomento de la identidad nacional, los valores compartidos y la integración cívica en lugar de apostar por políticas de igualdad de base etno-racial. En ellos, distintos paradigmas coexisten y se contradicen muy a menudo: la antidiscriminación y lo que estos autores denominan la «integración dura» en Francia marcada por la igualdad y la laicidad obligatoria que son conflictivas; la antidiscriminación y la cohesión comunitaria en el Reino Unido; y la asimilación y los retos de políticas multiculturales y antidiscriminatorias en los Países Bajos. Más que una pluralidad de paradigmas en estos casos asistimos a una lucha entre las fuerzas que intentan imponer su propia agenda a las sociedades multiculturales. En este contexto los partidos populistas no están lejos del poder.

Como acertadamente recuerda la Relatora Especial quizás la consecuencia más visible que ha tenido el resurgimiento del populismo nacionalista en la igualdad racial ha sido la escalada de incidentes de violencia, crímenes y discursos racistas y xenófobos en todo el mundo, incitando a nuevas y variadas formas del discurso del odio $^{29}$. Se dan así diversas prácticas en las que concurren los elementos para identificar el discurso del odio que señala Parekh (2005, pp. 433-438) se dirige contra un determinado grupo de personas, delimitándolo de forma precisa; establecido el

${ }^{28}$ Vid. Naciones Unidas, Asamblea General, A/73/305, op. cit., párr. 8.

29 Vid. Naciones Unidas, Asamblea General, A/73/305, op. cit., párrs. 17-24. 
objetivo del discurso, el sujeto estigmatiza a dicho colectivo asignándole algunos estereotipos indignos; y se considera que, por todas esas características, dicho grupo no puede integrarse en la sociedad con normalidad, de modo que se les aísla y menosprecia, tratándolos con aversión y hostilidad.

En todo caso, como señala Waldron (2012, pp. 37-38) puede ser que el concepto de discurso del odio resulte demasiado impreciso puesto que la referencia al término "odio» podría sugerir que lo que es objeto de reproche es el sentimiento de animadversión que se expresa hacia los miembros de un grupo minoritario. En realidad, lo significativo son los efectos perversos que tal discurso tiene en la configuración de una sociedad democrática y en la dignidad de los individuos que integran las colectividades contra las que se dirige. Ese es el rasgo que define el discurso del odio: su capacidad para atentar contra la dignidad humana.

Las disposiciones normativas internacionales ya analizadas ofrecen los mecanismos que permiten combatir dicho discurso. Así, por ejemplo, el artículo 4 ICERD, el 19 PIDCP y la recomendación general $n^{\circ} 35$ del CERD, y en el marco europeo disposiciones como la mencionada Decisión marco 2008/913/JAl del Consejo ${ }^{30}$, posibilitan una supervisión y una sanción del discurso del odio que, para que sea eficaz, exige la adopción de los marcos legislativos nacionales necesarios y la garantía de su debida aplicación.

La necesaria vigilancia sobre el impacto que la ideología del populismo nacionalista puede tener como amenaza para la igualdad racial o étnica, debe extenderse también al uso contemporáneo de la tecnología digital en la propagación de ideología neonazi y formas conexas de intolerancia. Como mantiene la Relatora Especial las tendencias y manifestaciones recientes de glorificación del nazismo, el neonazismo y otras prácticas contribuyen a exacerbar las formas contemporáneas de racismo, discriminación racial, xenofobia y formas conexas de intolerancia. Es fundamental insistir en la obligación de los Estados, en virtud del derecho internacional de los derechos humanos, de contrarrestar esas ideologías extremas en Internet, pero también poner en evidencia las responsabilidades de las empresas de tecnología ${ }^{31}$. Como el sector privado va a seguir desempeñando en el futuro un papel fundamental en la lucha contra la intolerancia en Internet, los Estados deben trabajar en colaboración con él. Las empresas de tecnología son responsables de invertir los recursos necesarios para garantizar que sus códigos de conducta y prácticas efectivas reflejen su compromiso con la igualdad racial, y con un concepto del derecho a la libertad de expresión que se ajuste a los principios y el derecho internacional de los derechos humanos. Es en ese punto en el que se cruza la acción privada de las empresas, la necesidad de activar su responsabilidad social y el respeto a los derechos humanos, en el caso concreto que nos ocupa para garantizar la igualdad racial y étnica.

Las empresas de tecnología no solo deben comprometerse para combatir el discurso de odio racista, como indica el articulo 4 ICERD, si no que además deben

\footnotetext{
30 Vid. European Parliament, Directorate General for Internal Policies, The European Legal Framework on Hate Speech, Blasphemy and Its Interaction with Freedom of Expression, Brussels, European Unión, 2015. En el caso concreto español, con la reforma del Código Penal de 2015 se fortalecen los delitos motivados por el odio y la motivación racista se considera una circunstancia agravante, realizando así la transposición de dicha Decisión Marco (Esteve, 2019, pp. 126-128).

${ }^{31}$ Vid. Naciones Unidas, Asamblea General, Informe de la Relator Especial sobre los derechos humanos de los migrantes, en cumplimiento de lo dispuesto en la resolución 72/156 de la Asamblea, presentado de conformidad con la resolución 68/179 de la Asamblea, sobre el uso contemporáneo de la tecnología digital en la propagación de intolerancia neonazi y formas conexas de intolerancia, A/73/312, de 7 de agosto de 2018, párrs. 49 a 51.
} 
alinearse con los Principios Rectores sobre las Empresas y los Derechos Humanos en la concreción de los objetivos de proteger, respetar y remediar (Solanes, 2016); y con el marco de regulación de contenido sugerido por el Relator Especial sobre la promoción y protección del derecho a la libertad de opinión y de expresión ${ }^{32}$. Tiene razón dicho Relator cuando señala que las empresas de Internet se han convertido en plataformas fundamentales para el debate, el acceso a la información, el comercio y el desarrollo humano. Sin embargo, a pesar de ese papel decisivo, pocas de las empresas tienen en cuenta los principios de derechos humanos en sus operaciones y prácticas, de ahí la importancia de insistir en el cumplimiento de los mencionados Principios Rectores (Márquez, 2015). Aunque estos no sean expresamente vinculantes, conectan con otros instrumentos de derechos humanos que sí lo son e invitan a que las empresas los adopten a través de la responsabilidad social corporativa. Dicha responsabilidad comporta, entre otras muchas cuestiones, una producción y un consumo responsable en el sentido amplio al que se refiere también la Agenda 2030 y la implementación de los ODS que en concreto recoge la igualdad de género (ODS 5) y la reducción de las desigualdades (ODS 10) que permiten combatir todo tipo de discriminaciones (Villavicencio, 2018).

\section{Protección frente a la discriminación}

Sin ánimo de realizar un estudio detallado y exhaustivo de la jurisprudencia del TEDH y del TJUE en relación a la discriminación racial o étnica, una aproximación a algunos de los asuntos más relevantes en ambas Cortes evidencia el significativo papel de ambas en aras de garantizar una igualdad formal y material ${ }^{33}$. En el conjunto de sentencias de dichos tribunales, y en las resoluciones emblemáticas, se toman progresivamente en consideración las diferentes causas a las que hemos visto que aluden los instrumentos internacionales de referencia para evitar dicha discriminación, sin embargo, no se ha incorporado, suficientemente todavía, la necesaria interpretación de carácter interseccional.

\subsection{La importancia de la jurisprudencia del TEDH y el TJUE}

En primer lugar, por lo que se refiere a la jurisprudencia del TEDH, como recuerda Rey (2012, pp. 293 y 317), hasta el año 2000 dicha jurisprudencia sobre la prohibición de discriminación del artículo 14 se puede sinterizar en tres aspectos: la discriminación como diferencia jurídica de trato no razonable ${ }^{34}$, la aplicación amplia y generosa de la doctrina del margen estatal de apreciación y la función complementaria y subsidiaria del artículo 14. Uno de los problemas de la cláusula que contempla el mencionado precepto es que no distingue entre el concepto general de igualdad concebida como razonabilidad jurídica del trato diferente, de la prohibición de

\footnotetext{
32 Naciones Unidas, Asamblea General, Consejo de Derechos Humanos, Informe del Relator Especial sobre la promoción y protección del derecho a la libertad de opinión y de expresión, de conformidad con la resolución 34/18 del Consejo, sobre la cuestión de la regulación del contenido en línea generado por los usuarios, A/HRC/38/35, de 6 de abril de 2018, párrs. 9 y 10.

${ }^{33}$ No se aborda la jurisprudencia de la Corte Penal Internacional sobre esta cuestión porque en realidad este Tribunal no ha incidido en las oportunidades que ofrece la ICERD, ni siquiera en el caso más significativo al respecto en la demanda por el Gobierno de Georgia c. la Federación de Rusia el 12 de agosto de 2008. Vid. ClJ, Application Instituting Proceedings, Application of the International Convention on the Elimination of All Forms of Racial Discrimination (Georgia v. Russian Federation), 12 August 2008 y Lucak (2012).

${ }^{34}$ Sobre esta cuestión es fundamental el caso Thlimmenos c. Grecia, n³ 34369/97, de 6 de abril de 2000, en el que el TEDH entiende que existe de discriminación cuando los Estados no traten de modo diferente, sin una justificación objetiva y razonable, a personas cuyas situaciones son sustancialmente distintas, la denominada discriminación por indiferenciación. Vid. Cobreros (2007) y Solanes (2017).
} 
discriminación por motivos como la raza, ante los cuales no basta con el criterio de la razonabilidad, sino que, como acertadamente mantiene el mencionado autor, el juicio debería ser más exigente incorporando criterios como la proporcionalidad o el escrutinio estricto, solo así puede perfilarse la distinción entre la discriminación en sentido amplio y en sentido estricto. En la jurisprudencia del TEDH sobre discriminación racial, constituyen un punto de inflexión dos sentencias: Nachova y otros c. Bulgaria, y D.H. y otros c. República Checa. A partir de estos referentes el Tribunal comienza a incorporar, lentamente y de forma discontinua, las categorías del derecho antidiscriminatorio procedentes de otros contextos en las que estas han sido más consolidadas, como el derecho anglosajón, las cuales también se han ido incorporando progresivamente al ordenamiento comunitario.

Como precedente de ambos asuntos, una referencia imprescindible en la jurisprudencia del TEDH en materia de discriminación es el caso Anguelova $c$. Bulgaria $^{35}$, en el que se alegaron móviles racistas asociados a la muerte de personas gitanas en dependencias policiales. El estricto estándar de prueba exigido hizo que el Tribunal no considerara que había existido discriminación racial, sin que resultara así de aplicación el artículo $14 \mathrm{CEDH}$, aunque sí se consideró que hubo vulneración del artículo $2 \mathrm{CEDH}$, relativo a la protección del derecho a la vida. El excelente voto particular del magistrado Bonello marcará el camino de la nueva jurisprudencia del TEDH. Dicho magistrado insistió en que no se podía diseñar una herramienta más efectiva para asegurar que la protección contra la discriminación racial sea ilusoria e inoperante, que exigir a una víctima un estándar de prueba que, en otras disputas de derecho civil, no se requiere. Además, señaló que debía invertirse la carga de la prueba, así cuando un miembro de un grupo minoritario desfavorecido sufriera daños en un entorno donde las tensiones raciales son altas la carga de probar que no ha habido discriminación correspondería a las autoridades nacionales.

En el asunto Nachova y otros c. Bulgaria ${ }^{36}$ se presentó un caso de violencia contra la minoría gitana. Dos jóvenes de origen romaní, fueron encarcelados, huyeron de la prisión, se refugiaron en el domicilio de un familiar y al intentar escapar fueron abatidos por la policía que profirió insultos racistas. Los familiares de las víctimas como demandantes invocaron la violación de los artículos 2 y 14 del CEDH. La Gran Sala relacionó ambos preceptos y los consideró vulnerados, entendiendo que el Estado está obligado a llevar a cabo una investigación efectiva en los casos de privación de la vida en que se alegue prejuicio racista. Las autoridades deben adoptar todas las medidas razonables para desenmascarar cualquier tipo de motivación racista cuando los funcionarios utilizan la fuerza. Por tanto, corresponde al Estado la carga de la prueba para demostrar la inexistencia de motivos discriminatorios por parte de los agentes. Este estándar de especial protección ha sido reiterado por la jurisprudencia posterior ${ }^{37}$.

Sin embargo, conviene recordar que esa misma jurisprudencia ha tenido algunas vacilaciones. Así, por ejemplo, en el caso Carabulea ${ }^{38}$ en el que una persona gitana falleció en dependencias policiales, el TEDH no entró a considerar si existía violencia racial dentro del marco de la prohibición del artículo $14 \mathrm{CEDH}$. De nuevo en este caso, como en los asuntos Anguelova son los dos interesantes votos particulares los que ponen en evidencia la necesidad de tomar en consideración la motivación

\footnotetext{
35 TEDH, Anguelova c. Bulgaria, $\mathrm{n}^{\circ} 38361 / 97$, de 13 de junio de 2002.

36 TEDH, Nachova y otros c. Bulgaria, n 43577/98 y 43579/98, de 6 de julio de 2005.

${ }^{37}$ Así, por ejemplo, la doctrina Nachova es reiterada por el TEDH en casos semejantes posteriores, entre ellos: Bekos y Koutropoulos c. Grecia, $\mathrm{n}^{\circ}$ 15250/02, de 13 de diciembre de 2005; Ognyanova y Chocan c. Bulgaria, $\mathrm{n}^{\circ} 46317 / 99$, de 23 de febrero de 2006 y Stoica c. Rumanía, $\mathrm{n}^{\circ} 42722 / 02$, de 4 de marzo de 2008.

${ }^{38}$ TEDH, Carabulea c. Rumanía, n 45661/99, de 13 de julio de 2010.
} 
racista apelando al precedente Nachova e insistiendo en la necesidad de que en el caso de violencia policial se analice la posible concurrencia de un móvil racista.

El segundo de los asuntos emblemáticos en materia de discriminación racial es el caso D.H. y otros contra República Checa ${ }^{39}$ en el que el TEDH apreció discriminación indirecta, contribuyendo a perfilar este concepto, en esta ocasión por motivos étnicos o raciales. En este supuesto la política educativa del Estado segregaba a la población infantil gitana o romaní en escuelas especiales, lo cual en opinión del Tribunal supone una violación del artículo $14 \mathrm{CEDH}$. Los recurrentes argumentaron, además, que la diferencia de trato no estaba justificada, suponía un trato degradante y les privaba del derecho a la instrucción (Añón, 2015). Es especialmente relevante en este caso la prueba basada en los datos estadísticos que, por comparación, permiten evidenciar la discriminación indirecta. Los votos disidentes criticaron que el Tribunal llevase a cabo una valoración del contexto social checo respecto a la posición de los gitanos. Asimismo, se invierte la carga de la prueba, que recae sobre el Estado demandado ${ }^{40}$. En aplicación de los criterios de esta resolución, la Gran Sala del Tribunal apreció también discriminación indirecta en el caso Orsus y otros c. Croacia ${ }^{41}$. No se trata de supuestos idénticos, puesto que, en esta ocasión los niños gitanos croatas no se ubicaron en colegios especiales, sino que se incorporaron a clases específicas por motivos lingüísticos (no hablaban croata, ya que, su lengua era el romaní), no raciales. A medida que iban aprendiendo croata eran trasladados a otras clases, obteniendo el mismo título. Además, el Tribunal insiste en la diferencia con el mencionado caso D.H. y otros, así como con otros como el caso Sampani y otros c. Grecia, recordando que la discriminación indirecta puede ser probada sin ayuda de estadísticas, siempre que los hechos muestren que la práctica en cuestión tiene un efecto negativo, no justificable. EI TEDH dio un giro a la sentencia de la sección primera de 17 de julio de 2008 y la Gran Sala entendió que las autoridades croatas no habían adoptado suficientes garantías para satisfacer las necesidades especiales de esta minoría como grupo desaventajado. La separación de los demandantes en clases especiales de gitanos en su educación primaria no había sido justificada, violando así el artículo $14 \mathrm{CEDH}$ en relación con el artículo 2 del Protocolo $\mathrm{n}^{\circ} 1$ (Solanes, 2017, p. 314).

Estas sentencias reflejan que los dos ámbitos de especial protección frente a la discriminación racial o étnica, son las agresiones racistas por parte de los agentes de la autoridad y el ejercicio del derecho a la educación. Aún así, son también reseñables otros aspectos que el TEDH ha tomado en consideración para apreciar dicha discriminación ${ }^{42}$.

Las resoluciones más recientes han afianzado esa jurisprudencia garantista que permite combatir los estereotipos socialmente arraigados, por ejemplo, en el caso de la comunidad gitana. Así, en el asunto Lingurar c. Rumanía ${ }^{43}$, una familia romaní de nacionalidad rumana fue víctima de una redada por parte de 85 agentes de policía en una comunidad gitana en Rumanía. Los agentes irrumpieron en su casa, les golpearon y se llevaron a dos personas para interrogarlas en comisaría, poniéndolas

\footnotetext{
39 TEDH, D.H. y otros c. la República Checa, n 57325/00, de 13 de noviembre de 2007.

40 Esta sentencia constituye un punto de referencia en la jurisprudencia desarrollada posteriormente sobre segregación en la escuela por motivos racistas, por ejemplo, en asuntos como TEDH, Sampani y otros c. Grecia, de 5 de junio de 2008, n 32526/05; y TEDH, Horvath y Kiss c. Hungría, n 11146/11, de 29 de enero de 2013.

41 TEDH, Orsus y otros c. Croacia, n 15766, de 16 de marzo de 2010.

42 Entre ellos, además de los dos mencionados vid. asunto V.C. C. Eslovaquia, n 18968/07, de 8 de noviembre de 2011, sobre esterilización de mujeres romaníes sin consentimiento informado. Vid. Casado (2013) y Rey (2012).

43 TEDH, Lingurar c. Rumanía, n 48474/14, de 16 de abril de 2019.
} 
en libertad al día siguiente tras acusarlas de cortar madera ilegalmente. La familia denunció los hechos y la investigación concluyó que las heridas de los hombres fueron causadas como consecuencia de su resistencia a la autoridad, mientras que las de las mujeres podían ser debidas a un "comportamiento específico de los gitanos», refiriéndose a conductas autolesivas. El fiscal señaló que la mayoría de las personas de esa comunidad gitana eran conocidas por actuar en contra de la ley y ser agresivas con la policía. En este escenario las autoridades judiciales rumanas estimaron que no hubo uso de fuerza excesivo por parte de la policía y negaron la existencia de una práctica sistemática de ataques policiales contra dicha comunidad.

EI TEDH, atendiendo al artículo $3 \mathrm{CEDH}$, consideró que las heridas que se certificaban en los informes médicos evidenciaban que se había alcanzado el mínimo nivel de severidad requerido para determinar una violación de dicho precepto. En cuanto a la vulneración del artículo $14 \mathrm{CEDH}$, el Tribunal tomó en consideración que el plan de intervención de la policía, anterior a la redada, aludía de forma expresa a la comunidad gitana como objetivo y mencionaba el supuesto comportamiento antisocial y la alta tasa de criminalidad de las personas romanís. Además, también apreció la mencionada referencia del fiscal, durante la investigación a lo que consideraba el «comportamiento específico de los gitanos» para acusar a las mujeres y defender la redada en base a los problemas generados por la comunidad gitana y su comportamiento criminal ${ }^{44}$.

Un aspecto fundamental de este caso es que el TEDH utiliza la expresión «racismo institucional», sentando así un importante precedente. En este caso es evidente que la actuación de la policía seguía un perfil étnico, en la línea que se señalaba anteriormente. En opinión del Tribunal, en situaciones como la analizada en las que hay evidencia de patrones de violencia y la intolerancia contra una minoría étnica, las obligaciones que incumben a los Estados miembros exigen un estándar más alto de respuesta a supuestos incidentes motivados por prejuicios. A partir de las pruebas presentadas, el Tribunal entiende que en el Estado en cuestión las comunidades romaníes se enfrentan a menudo al «racismo institucional» y son propensas a un uso excesivo de la fuerza por parte de las autoridades encargadas de hacer cumplir la ley. En este contexto, el mero hecho de que los estereotipos sobre el denominado "comportamiento romaní» figuren en la evaluación de la situación por parte de las autoridades puede dar lugar a sospechas de discriminación por motivos étnicos. Dichas sospechas, junto con las que considera modalidades de intervención del 15 de diciembre de 2011, deberían haber llevado a las autoridades a adoptar todas las medidas posibles para investigar si la discriminación podía haber desempeñado o no un papel en los hechos. Sin embargo, las autoridades y los tribunales nacionales desestimaron las alegaciones de discriminación y criminalización de la comunidad romaní formuladas por los demandantes sin ningún análisis en profundidad de todas las circunstancias pertinentes del caso. Por todo ello, el TEDH entiende que se vulneraron los derechos de las personas demandantes recogidos en el artículo 14, en conjunción con el artículo 3 del Convenio ${ }^{45}$.

Esta sentencia con las reseñadas anteriormente muestra los evidentes avances jurisprudenciales en la materia, aunque sigan existiendo zonas que requieren de una mayor clarificación y una utilización más depurada de las categorías del

\footnotetext{
44 Ibídem, párrs. 69,75 y 78 y 82

45 Ibídem párrs. 80 a 82 .
} 
derecho antidiscriminatorio ${ }^{46}$. Esa es precisamente la línea de futuro en la que debe avanzar el TEDH, combatiendo el racismo institucional.

Por lo que se refiere al TJUE, a pesar de la gran novedad que supuso en su momento la ya analizada Directiva 2000/48, la jurisprudencia del TJUE es muy escasa, lo que evidencia la necesidad de seguir ahondado igualmente en el fortalecimiento de las categorías del derecho antidiscriminatorio. Como muestra significativa en el ámbito comunitario pueden citarse como referentes en la lucha contra la discriminación racial los asuntos Firma Feryn y CHEZ Razpredelenie Bulgaria.

En el asunto Firma Feryn ${ }^{47}$, uno de los directores de dicha empresa especializada en la venta e instalación de puertas, declaró que la empresa buscaba instaladores pero que no podía contratar a personas extranjeras, puesto que sus clientes eran reacios a que estas accedieran a sus viviendas. El centro belga para la igualdad de oportunidades y la lucha contra el racismo, aunque no existía ninguna víctima concreta, presentó la demanda en el ámbito interno belga (evidenciando así también la importancia de este organismo) y al llegar al Tribunal de Apelación de lo Social de Bruselas este planteó la petición de decisión prejudicial ante el TJUE. En palabras del Tribunal «las declaraciones públicas mediante las que un empleador da a conocer que, en el marco de su política de contratación, no empleará a trabajadores de determinado origen étnico o racial bastan para presumir la existencia de una política de contratación directamente discriminatoria, en el sentido del artículo 8, apartado 1, de la Directiva 2000/48». Dicho Tribunal aceptó la legitimación activa, aunque no existieran aun víctimas concretas, e invirtió la carga de la prueba de tal forma que correspondía a la parte demandada demostrar que no se había vulnerado el principio de igualdad de trato.

En la línea que sostiene Aguilar (2014, p. 43) el alcance de la característica de «origen racial o étnico» no es exactamente el mismo en el ámbito comunitario y en $\mathrm{CEDH}$, ya que, la Directiva excluye la nacionalidad del concepto de raza o etnia, mientras que en el CEDH se alude a la «nacionalidad» o el «origen nacional» como una característica específica. Sin embargo existe jurisprudencia que pone de relieve que la nacionalidad puede entenderse como un elemento constitutivo de la etnia, pero la exclusión no obedece a que la discriminación por motivos de nacionalidad se permita en el derecho comunitario, sino a que se regula en el contexto de la legislación sobre libre circulación de personas.

En el segundo asunto CHEZ Razpredelenie Bulgaria AD c. Komisia za zashtita ot diskriminatsia $[G C]^{48}$ la petición de decisión prejudicial fue planteada por el Administrativen sad Sofia-grad de Bulgaria. El caso trae causa de la queja presentada por la demandante en la que argumentó que la instalación de los contadores eléctricos en los postes del tendido eléctrico aéreo a una altura de seis a siete metros se debía a que se encontraba en un barrio urbano poblado principalmente por personas de origen gitano y dicha instalación la ponía en desventaja en comparación con otros

\footnotetext{
${ }^{46}$ Así ocurrió, por ejemplo, en el caso Muñoz Díaz, en el que el TEDH argumenta desde el derecho de igualdad y no desde el derecho a no sufrir discriminación racial (Rey, 2017, p. 161). TEDH, Muñoz Díaz c. España, n 49151/07, de 8 de diciembre de 2009.

47 TJUE, Centrum voor gelijkheid van kansen en voor racismebestrijding c. Firma Feryn NV, C-54/07, de 10 de julio de 2008.

48 TJUE, C-83/14, CHEZ Razpredelenie Bulgaria AD c. Komisia za zashtita ot diskriminatsia [GC], de16 de julio de 2015. Cfr. STJUE, de 31 de enero de 2013, Valeri Hariev Belov c. Chez Elektro Bulgaria $A D$ y otros. Petición de decisión prejudicial: Komisia za zashitita ot diskriminatsia-Bulgaria, C-394/11. También se aborda el problema sobre la discriminación racial en la TJUE, Meister, C-415/10, de 19 de abril de 2012, y TJUE, Runevic-Vardyn, C-391/09, de 12 de mayo de 2011.
} 
clientes cuyos medidores estaban ubicados en lugares accesibles. Sobre la base de esta consideración, el TJUE concluyó que la Directiva de igualdad racial se aplicaba a la política del proveedor de electricidad en este caso y que correspondía a la jurisdicción búlgara decidir si la práctica podría justificarse objetivamente.

Este caso permitió al TJUE aclarar distintos aspectos del concepto de discriminación, la diferencia entre la discriminación directa e indirecta y lo que constituye un elemento adecuado de comparación. Así expresamente mantiene que el concepto de «desventaja particular» en el sentido del artículo 2.2. b), de la Directiva 2000/43 no designa un caso especialmente relevante, evidente y grave de desigualdad, sino que establece que la disposición, criterio o práctica considerados desfavorecen particularmente a las personas de un origen racial o étnico concreto. La medida indicada solo puede justificarse objetivamente por la voluntad de garantizar la seguridad de la red de transporte de electricidad y un seguimiento apropiado del consumo de electricidad a condición de que dicha medida no exceda de los límites de lo que es apropiado y necesario para realizar esos objetivos legítimos y de que los inconvenientes causados no sean desmesurados en relación con los objetivos perseguidos por ese medio. Apreciar si existen otros medios apropiados o menos restrictivos o si la práctica perjudica en grado desmesurado el interés legítimo de los usuarios corresponde al tribunal remitente.

Como se desprende de la jurisprudencia de ambos tribunales queda todavía un largo camino que recorrer en este ámbito para consolidar la prohibición de la discriminación racial y enfocarla, también, desde la perspectiva interseccional que antes se apuntaba. Incorporar la discriminación interseccional supondría tomar en consideración que en una situación concurren múltiples patrones que actúan e interactúan entre sí al mismo tiempo, de tal manera que son inseparables y dan lugar a tipos particulares de discriminación.

EI TJUE ha recordado que no puede ampliar los motivos del artículo 21 de la Carta de los Derechos Fundamentales de la Unión Europea ${ }^{49}$, de tal forma, que una posibilidad de esta lectura integrada sería combinar los motivos en la lista existente, sin ser considerado como un nuevo subgrupo ${ }^{50}$.

En cambio, el TEDH en su jurisprudencia más reciente, parece ir reconociendo de forma tácita la discriminación interseccional, cuando se le ha planteado, sin adoptar claramente la terminología de discriminación interseccional, pero sí su enfoque ${ }^{51}$. Este es precisamente, en mi opinión, el camino por el que deben transitar ambos Tribunales para conseguir una jurisprudencia más garantista en la lucha contra la discriminación.

4.2. Los organismos especializados para la protección de la igualdad y la no discriminación

Otra forma de protección frente a la discriminación es la que encontramos en el ámbito comunitario, a través de las diferentes disposiciones de derecho antidiscriminatorio que contemplan la creación de organismos especializados. Las

\footnotetext{
49 Por ejemplo, en casos como TJUE, C-310/10, Ministerul Justiţiei şi Libertăţilor Cetăţeneşti c. Ştefan Agafiţei et autres, 7 juillet 2011; y TJUE, C-406/15, Petya Milkova c. Izpalnitelen direktor na Agentsiata za privatizatsia i sledprivatizatsionen kontrol, 9 marzo 2017.

${ }^{50}$ European Union Agency for Fundamental Rights (FRA) and Council of Europe, Handbook on European non-discrimination law, Luxembourg: Publications Office of the European Union, 2018, pp. 35 y 67.

51 Vid., entre otras, TEDH, N.B. c. Eslovaquia, ${ }^{\circ}$ 29518/10, de 12 de junio de 2012; TEDH, B.S. c. España, $n^{\circ}$ 47159/08, de 24 de julio de 2012; TEDH, S.A.S. c. France [GC], $\mathrm{n}^{\circ}$ 43835/11, de 1 de julio de 2014; TEDH, Carvalho Pinto de Sousa Morais c. Portugal, n 17484/15, de 25 de julio de 2017.
} 
Directivas europeas sobre igualdad de trato requieren a los Estados miembros para que designen un organismo que la promocione en función de las diferentes materias de las que se ocupan. La ya mencionada Directiva para la promoción de la igualdad de trato con respecto a la raza u origen étnico, en su artículo 13, hace referencia a dicho organismo señalando que puede formar parte de los servicios responsables a nivel nacional de la defensa de los derechos humanos o de la salvaguardia de los derechos individuales. Entre las funciones que les corresponden a dichos organismos se incluyen las imprescindibles para combatir la discriminación y fomentar la igualdad, entre ellas, la de prestar asistencia independiente a las víctimas de discriminación a la hora de tramitar sus reclamaciones por discriminación, realizar estudios independientes, publicar informes independientes y formular recomendaciones sobre cualquier cuestión relacionada con la discriminación racial o étnica.

Otras disposiciones apelan igualmente a la necesidad de crear y fortalecer los organismos de igualdad, como la Recomendación de la Comisión de 22 de junio de 2018 sobre normas para los organismos de igualdad ${ }^{52}$, la Opinión sobre los órganos de igualdad de 2011 del Comisionado de Derechos Humanos del Consejo de Europa $^{53}$, la Recomendación $n^{0} 2$ de la ECRI sobre los organismos de igualdad ${ }^{54}$ y los Principios de París ${ }^{55}$. Asimismo, esa necesidad ha quedado patente, entre otros, en el informe conjunto de 2014 sobre la aplicación de las Directivas 2000/43/CE y 2000/78/CE ${ }^{56}$ y en el llamamiento al respecto del Parlamento Europeo su Resolución de $2015^{57}$.

Como señala la Comisión Europea ${ }^{58}$, los diferentes Estados de la Unión han creado estos tipos de organismos para combatir la discriminación, pero el funcionamiento de estos es muy diverso. Así, existen diez organismos de igualdad que actúan atendiendo a una lista de motivos abierta (en Bulgaria, Estonia, Finlandia

52 Comisión Europea, Recomendación (UE) 2018/951 de la Comisión, de 22 de junio de 2018 sobre normas relativas a los organismos para la igualdad. Se aplica en relación a las Directivas 2000/43/CE, 2004/113/CE, 2006/54/CE y 2010/41/UE. Vid. Ammer, Crowley, Liegl, Holzleithner, Wladasch and Yesilkagit (2010).

${ }^{53}$ Consejo de Europa, Comisionado para los Derechos Humanos (2011), Opinión del Comisionado para los Derechos Humanos a nivel nacional. Estructuras para promover la igualdad, Estrasburgo, Consejo de Europa, 21 de marzo de 2011.

${ }^{54}$ Consejo de Europa, Comisión Europea contra el Racismo y la Intolerancia (ECRI), Recomendación de política general $n^{\circ} 2$ sobre los órganos especializados en la lucha contra el racismo, la xenofobia, el antisemitismo y la intolerancia a nivel nacional, Estrasburgo, Consejo de Europa, aprobada el 13 de junio de 1997 y revisada el 7 de diciembre de 2017.

55 Naciones Unidas, Asamblea General de las Naciones Unidas, Principios relativos al estatuto y funcionamiento de las instituciones nacionales de protección y promoción de los derechos humanos, adoptados por la Comisión de Derechos Humanos de las Naciones Unidas en la Resolución 1992/54, de 1992, reafirmada por la Asamblea General con la Resolución 48/134 de 20 de diciembre de 1993 y las observaciones generales sobre la interpretación y aplicación de dichos principios por el Comité Internacional de Coordinación de las Instituciones Nacionales para la Promoción y la Protección de los Derechos Humanos, en su tenor de 21 de febrero de 2018.

${ }^{56}$ Comisión Europea, Informe conjunto sobre la aplicación de la Directiva 2000/43/CE del Consejo, de 29 de junio de 2000, relativa a la aplicación del principio de igualdad de trato de las personas independientemente de su origen racial o étnico ("Directiva de igualdad racial») y la Directiva 2000/78/CE del Consejo, de 27 de noviembre de 2000, relativa al establecimiento de un marco general para la igualdad de trato en el empleo y la ocupación ("Directiva de igualdad en el empleo»), de 17 de enero de 2014, COM (2014) 2 final.

57 Parlamento Europeo, Resolución de 8 de octubre de 2015, sobre la aplicación de la Directiva 2006/54/CE del Parlamento Europeo y del Consejo, de 5 de julio de 2006, relativa a la aplicación del principio de igualdad de oportunidades e igualdad de trato entre hombres y mujeres en asuntos de empleo y ocupación [2014/2160(INI)], C 349/56, Diario Oficial de la Unión Europea, de 17 de octubre de 2017.

${ }^{58}$ European Commission, European network of legal experts in gender equality and non-discrimination (2018), Equality bodies making a difference, Brussels: European Commission, Directorate-General for Justice and Consumers, Directorate D- Equality and Union citizenship, August 2018, p. 7. 
Hungría, Letonia, Liechtenstein, Polonia, Rumanía, Eslovaquia y Eslovenia); seis organismos de igualdad que tienen un mandato alineado con los motivos del artículo 19 TFUE, es decir, género, origen racial o étnico, religión o creencia, discapacidad, edad y orientación sexual (en Austria, Dinamarca, Estonia, Alemania y Luxemburgo); y diez organismos de igualdad que se ocupan de un único ámbito, de ellos siete trabajan por motivos de género, dos por motivos de origen racial y étnico y uno por motivos de discapacidad (género: en Bélgica, Croacia (incluye motivos de identidad y expresión de género, orientación sexual, estado civil o familiar), Finlandia, Islandia, Italia y Portugal; origen racial o étnico: en Portugal y España; y discapacidad en Liechtenstein).

Ahora bien, aunque los Estados han hecho el esfuerzo institucional de seguir los mandatos de las diferentes directivas en cuanto a la constitución de estos organismos, los resultados de su actividad son diferentes en función del interés político que suscitan en la práctica. Así, como recuerda también la propia Comisión, el contexto para los organismos de igualdad en ocho países es de hostilidad política (en Bulgaria, Croacia, Chipre, Italia, Polonia, Rumanía, Suecia y el Reino Unido), aunque la actitud dominante es el desinterés político que se da en otros doce países (en Austria, Bélgica, Estonia, Finlandia, Grecia, Hungría, Liechtenstein, Luxemburgo, Lituania, Eslovaquia, Eslovenia y España). Sin embargo, en otros siete Estados (Francia, Alemania, Islandia, Irlanda, Letonia, Países Bajos y Portugal) existe un contexto político de apoyo, que fomenta el potencial y el impacto de los organismos de igualdad.

El imprescindible compromiso político, como punto de partida, debe conjugarse con el correcto desempeño de las funciones que a estos organismos corresponde para que efectivamente puedan ser instrumentos de protección frente a la discriminación. En ese sentido, la mencionada Recomendación de la Comisión de 22 de junio de 2018 señala, dentro del mandato de los organismos de igualdad, la necesidad de asegurar la asistencia, los estudios y los informes independientes, realizando recomendaciones y fomentando la igualdad. Para ello, es imprescindible incentivar dos de las características de las que más han adolecido, en mi opinión, estos organismos desde su creación: la independencia y la eficacia.

Ambas exigencias requieren prestar atención a aspectos que la Recomendación señala tales como la posición que ocupan dichos organismos en la estructura administrativa, los procedimientos de nombramiento y despido de personal, y la incompatibilidad de funciones. Un aspecto esencial será la asignación de presupuesto y sus procedimientos para la tramitación de recursos humanos, técnicos y financieros, de lo contrario no sería posible ejercer sus competencias con eficacia, en un tiempo razonable y en los plazos legalmente establecidos al efecto. Otra cuestión necesaria para la eficacia de estos organismos es que se incentive la presentación de denuncias, el acceso y la accesibilidad (esta última cuestión atendiendo a las adaptaciones que sean necesarias de acuerdo con lo establecido en la Convención de las Naciones Unidas sobre los Derechos de las Personas con Discapacidad). Para promocionar el acceso es necesario, entre otras cuestiones, que el procedimiento para presentar denuncias ante los organismos para la igualdad sea sencillo y gratuito.

Ambos aspectos han sido parcialmente criticados, por ejemplo, en el caso del España, en contraste con otros Estados como Francia. Así se consideró que al articular el Consejo para la Eliminación de la Discriminación Racial o Étnica ${ }^{59}$, hubiera

59 En España la ya mencionada Ley 62/2003 en su artículo 33, estableció la creación de un organismo de igualdad de trato y no discriminación de las personas por el origen racial o étnico (transponiendo así 
sido necesario incentivar en las prácticas, de manera más decidida (puesto que, se menciona, pero parece una mera insistencia retórica), la independencia del poder público y político y concretar una dotación presupuestaria anual que figurase en los Presupuestos Generales del Estado (Esteve, 2013, pp. 52-53). Ambas son cuestiones que pueden abordarse observando las propuestas de la Recomendación y en el marco de una regulación integral en materia de igualdad que es inaplazable.

Por otra parte, la pluralidad de organismos destinados a combatir la discriminación por diferentes motivos exige que exista una coordinación interna y una cooperación exterior. Entre los organismos de un mismo Estado, la coordinación regular puede permitir que los principios de no discriminación se apliquen de manera coherente atendiendo al análisis múltiple en el que se viene insistiendo. Respecto a la cooperación es imprescindible que los Estados miembros permitan, por ejemplo, que los organismos para la igualdad dialoguen con las autoridades nacionales competentes y los organismos dentro de cada Estado.

Como acertadamente señala la Comisión ${ }^{60}$, es necesario actuar desde diferentes niveles para impulsar estos organismos de igualdad y que realmente sean un instrumento efectivo y eficaz. El nivel europeo tiene una importante contribución que hacer para garantizar las condiciones externas necesarias, incidiendo en medidas como, el compromiso de los funcionarios públicos de los gobiernos nacionales en el diálogo en curso sobre el potencial de los organismos de igualdad, el desarrollo de normas internacionales sobre organismos de igualdad desde la perspectiva de la citada Recomendación de la Comisión Europea; el desarrollo y supervisión para establecer la suficiencia de financiación para estos organismos de igualdad tomando en consideración parámetros como el tamaño del Estado miembro, su población; el nivel y la naturaleza de incidentes de discriminación denunciados y no denunciados; el alcance, capacidad y contribución de otros organismos que trabajan en este ámbito; los costes de la implementación de las competencias de un organismo de igualdad para conseguir impacto; y la escala del presupuesto nacional.

En la dimensión estatal, de las diferentes condiciones externas necesarias para que los organismos de igualdad sean independientes y eficaces, considero reseñables tres que no han sido suficientemente desarrolladas hasta el momento. En primer lugar, la introducción de disposiciones para la discriminación interseccional (en el sentido antes señalado) en la legislación de igualdad de trato para permitir abordar asuntos desde ese enfoque y conseguir una mayor eficacia. En segundo lugar, es necesario un procedimiento transparente, basado en competencias y participativo, y una reestructuración de la rendición de cuentas exigida al organismo de igualdad de manera que mantenga al Parlamento informado a través de su informe anual, pero que tenga una única responsabilidad limitada a la auditoría estatal relevante. Por último, una provisión de fondos adecuada, que le permita desempeñar sus funciones,

la directiva 2000/43) el denominado ahora Consejo para la Eliminación de la Discriminación Racial o Étnica (CEDRE) siendo especialmente relevante en el mismo el Servicio de Asistencia y Orientación a Víctimas de Discriminación Racial o Étnica. Dos normas posteriores concretaron su funcionamiento: el Real Decreto 1262/2007, de 21 de septiembre, por el que se regula la composición, competencias y régimen de funcionamiento del Consejo para la Promoción de la Igualdad de Trato y no Discriminación de las Personas por el Origen Racial o Étnico (BOE $n^{\circ} 237$, de 3 de octubre de 2007) y el Real Decreto 1044/2009, de 29 de junio, por el que se modifica el Real Decreto 1262/2007, de 21 de septiembre, por el que se regula la composición, competencias y régimen de funcionamiento del Consejo para la Promoción de la Igualdad de Trato y no Discriminación de las Personas por el Origen Racial o Étnico (BOE $n^{\circ} 177$, de 23 de julio de 2009). Varias de las recomendaciones que realiza la ECRI a España tiene que ver con este organismo vid. ECRI, Informe de la ECRI sobre España (quinto ciclo de supervisión), adoptado el 5 de diciembre de 2017 y publicado el 27 de febrero de 2018, CRI (2018) 2.

${ }^{60}$ European Commission, European network of legal experts in gender equality and non-discrimination (2018), Equality bodies making a difference, op. cit., pp. 130-131. 
con competencias para realizar legalmente decisiones vinculantes e imponer sanciones, tener una posición legal ante los tribunales y promover estándares para una buena equidad y diversidad práctica.

Un último grupo de medidas que involucraran a los organismos de igualdad, colectivamente o individualmente, podrían servir para fortalecerlos. Entre ellas, la evaluación de las operaciones internas a la luz de las Recomendaciones, por ejemplo, de la ECRI; la creación de sistemas de datos que permita un seguimiento coherente de indicadores comunes en todas las jurisdicciones; y la mejora de la naturaleza y la calidad de la asistencia.

\section{A modo de conclusión}

Los estándares normativos afianzados en las últimas décadas han sido fundamentales para consolidar en el ámbito internacional y nacional un amplio marco jurídico que permita consolidar la lucha contra la discriminación. En la dimensión internacional, los informes de los relatores especiales alertan tanto de la necesidad inaplazable de fortalecer las medidas jurídicas para combatir la discriminación como de la realidad a nivel mundial que refleja un aumento significativo de actos racistas, de discriminación racial, xenofobia y de otras formas conexas de intolerancia que incitan al odio y obstaculizan la coexistencia pacífica. La vigilancia en el cumplimiento de las obligaciones internacionales por parte de los Estados, y la visibilidad de los supuestos de incumplimiento, hace que sea necesario poner en valor el papel que desempeñan los relatores especiales y reforzar su papel. Así, podría atenderse a alguna de las propuestas que la Asamblea ha realizado a través de sus resoluciones para combatir la discriminación entre ellas, por ejemplo, la de examinar los modelos nacionales de mecanismos que miden la igualdad racial y su contribución a la erradicación de la discriminación racial, de manera que pueda reflejarse en el informe de la relatora especial los problemas, éxitos y mejoras prácticas, y se exprese la preocupación por la falta de progreso en esta cuestión ${ }^{61}$.

Desde la ICEDR hasta el CEDH y los Protocolos, junto con la intensa labor de los organismos de supervisión, especialmente del CERD y la ECRI, se ha realizado una regulación y aplicación a través de los informes, recomendaciones y sugerencias de mejora, que permite avanzar en el fortalecimiento del derecho antidiscriminatorio. Las directrices están establecidas y deberían ser el estímulo para que los Estados cumplan con sus obligaciones y propicien, si es necesario, cambios legislativos acordes a las disposiciones internacionales, sabiendo, como se recoge en las recomendaciones analizadas, que como exigencia mínima y sin excluir otras medidas, es indispensable una legislación completa contra la discriminación racial en derecho civil, administrativo y penal, para luchar con eficacia contra el discurso de odio racista.

Con este marco, más que insistir en el incremento de las disposiciones normativas que han supuesto, como se ha señalado, grandes avances, conviene atender a una doble línea de acción: por una parte, la correcta implementación de las mismas para que sean un referente indiscutible también contra las nuevas formas de discriminación; y, por otra, una cuidada interpretación clarificadora, extensiva y garantista de las disposiciones existentes. En ese sentido, es imprescindible atender a las mejoras que desde los mecanismos de seguimiento e investigación alientan a una interpretación más garantista de las disposiciones vigentes para combatir de

61 Naciones Unidas, Asamblea General, Resolución aprobada por la Asamblea General el 22 de diciembre de 2018, A/RES/73/262, op. cit., párr. 22. 
manera eficaz los actos de discriminación. Sigue existiendo todavía un desfase entre las posibilidades de las figuras que se recogen en el derecho antidiscriminatorio y su operatividad práctica. La mayoría de Estados, ha adoptado nuevas normas e instrumentos para luchar contra el racismo y la discriminación, pero persisten importantes déficits que generan disfunciones prácticas. Varios ejemplos de ese desencaje, como se ha señalado, se encuentran en los asuntos que han llegado a la jurisdicción internacional (tomando también en consideración la dificultad añadida de llegar a este nivel), entre ellos claramente los que tienen que ver con la actuación de las fuerzas y cuerpos de seguridad tanto en el uso de perfiles raciales y étnicos como en la utilización de la violencia.

Por otra parte, la persistencia de las que pueden considerarse como formas tradicionales de discriminación, entre ellas la que va unida a la condición de extranjero, y las que adoptan nuevas formas como las propias del populismo nacionalista, así como de diferentes mecanismos para hacerlas efectivas, entre ellas claramente las redes sociales, exige la estricta aplicación de la normativa vigente, la actuación diligente por parte de los Estados (en la línea de una diligencia debida que emana de las obligaciones internacionales asumidas) y el fortalecimiento de los instrumentos de protección.

En efecto, el marco jurídico adecuado actual permite combatir los actos discriminatorios, sin embargo, es imprescindible para seguir avanzando que este se aplique correctamente por los operadores jurídicos y que, al mismo tiempo, las víctimas puedan acceder a un sistema que las ampare y las proteja. En dicha dimensión es especialmente relevante el papel que ha desempeñado la jurisprudencia y los organismos para la promoción de la igualdad y la no discriminación.

Como evidencia la jurisprudencia analizada se han consolidado estándares que pueden servir para avanzar en la lucha contra la discriminación. EI TJUE con los asuntos Firma Feryn y CHEZ Razpredelenie Bulgaria ha iniciado una importante línea jurisprudencial que está llamada a consolidarse. Sin embargo, en este ámbito son especialmente relevantes las líneas apuntadas desde el TEDH. En primer lugar, la exigencia para las autoridades de los Estados de llevar a cabo una investigación efectiva ante todo indicio de discriminación, ello permitiría ajustar mejor la imposición de condenas por los mismos. De esta manera, se desplaza la carga de la prueba de forma que es el Estado, y no las víctimas, quien debe justificar que la medida que se haya adoptado no obedece a un prejuicio que genera una discriminación.

Dicha obligación de llevar a cabo una investigación efectiva conecta con la necesidad, puesta de manifiesto también por parte de los organismos internacionales como una preocupación constante, de combatir el uso de perfiles raciales y étnicos. Como ha constatado el TEDH en el mencionado caso Lingurar c. Rumanía existe un racismo institucional en el que encaja el uso de los perfiles, atendiendo a estereotipos incluso fobotipos que recaen de modo reincidente sobre determinados grupos que son incompatibles con las responsabilidades de los Estados. Se constata así la importancia de los prejuicios y estereotipos en el racismo que surgen de la dominación que pueden ejercer las propias instituciones que contribuyen, de modo determinante, a consolidar la opresión hacia determinados grupos que se genera con patrones sociales discriminatorios que están integrados constantemente en los sistemas normativos. Ese racismo institucional coloca a determinados sujetos en situación de constante excepción porque no los concibe desde las reglas básicas del Estado de Derecho, si no desde la dominación.

Para combatir ese racismo institucional debe tenerse presente, también, la necesidad de formación de todos los actores implicados en posibles actos de 
discriminación, desde los jueces y fiscales, hasta los cuerpos y fuerzas de seguridad del Estado de tal manera que, progresivamente, se consoliden buenas prácticas y se sensibilice a la sociedad de las consecuencias de la discriminación racial.

En segundo lugar, la jurisprudencia del TEDH, ha asentado también la importancia del valor probatorio de los datos estadísticos, como muestra objetiva, en los supuestos de discriminación objetiva. Esta trascendencia que han adquirido los datos invita a afrontar una de las críticas permanentes que han reflejado también los informes y recomendaciones de los organismos internacionales: la necesidad de recopilación de datos. Ciertamente, el tratamiento de los datos sobre igualdad de trato es responsabilidad de los Estados, de tal manera que sea posible conocer los actos discriminatorios. Si además estos son desagregados por sexo, edad, origen étnico, religión, etc., pueden aportar información relevante a efectos probatorios. Asimismo, la articulación de bases permite disponer de información tan necesaria como las relativas a la cantidad de casos judicializados y las sanciones impuestas. Esta responsabilidad estatal en relación a la configuración de estadísticas es compatible con la protección de datos, de hecho, es uno de los supuestos que sistemáticamente se incluye, siempre que se sigan las normativas al respecto.

Por lo que se refiere a los organismos especializados para la promoción de la igualdad y la no discriminación, como se ha reseñado, han recibido diferentes críticas, que invitan a mejorar su funcionamiento, pero no a negar el importante papel que pueden desempeñar. La mencionada Recomendación 2018/951 de la Comisión que se aplica a los organismos para la igualdad establecidos en virtud de las Directivas en materia de igualdad, ofrece las pautas ineludibles y urgentes para la configuración futura de estos organismos. La diversidad de dichos organismos ha mostrado que pueden realizar funciones esenciales en la promoción de la igualdad, pero que en la mayoría de casos no han recibido el impulso político imprescindible que redunda en una imposibilidad material de acometer su misión. Entre las diferentes opciones que existen a la hora de articular estos organismos (también en lo relativo a si deben de ocuparse de uno o varios de los motivos de discriminación) lo relevante, en mi opinión, no es tanto dónde se incardinen, si no el hecho de que se consiga que efectivamente funcionen como organismos de supervisión, con carácter transversal en el conjunto de las administraciones públicas, en materia de igualdad.

Desde esa perspectiva, las reflexiones que se plantean, por ejemplo, en España acerca de si el CEDRE debe ser un organismo autónomo o ubicado dentro del Defensor de Pueblo, en cuanto que este es un organismo independiente que puede iniciar de oficio una investigación y proponer la modificación normativa, si bien supervisa básicamente la actividad de las administraciones públicas españolas, no son prioritarias. No se trata tanto de la ubicación cuanto de la función real del organismo. En ese sentido, lo fundamental es la independencia y la eficacia. No existe independencia posible sin asignación de recursos, materiales y humanos. Tan importante como la dotación presupuestaria, es la posición que dichos organismos ostenten en la estructura administrativa general y los procedimientos de designación de las personas formadas a tal efecto, con especial atención a quienes ocupen los puestos de liderazgo, para que no existan incompatibilidades.

Además, la eficiencia de los organismos para la promoción de la igualdad exige incentivar las funciones relativas a la realización de estudios e informes independientes y la formulación de recomendaciones, pero también requiere impulsar la asistencia independiente y la presentación de denuncias ante los mismos. Dentro de la asistencia independiente a las víctimas podrían desarrollarse funciones que hasta ahora no se han explotado lo suficiente en diferentes Estados, tal como señala la recomendación, entre ellas, por ejemplo, recibir y tramitar denuncias individuales o 
colectivas, proporcionar asesoramiento jurídico también para tramitar las denuncias, participar en actividades de mediación y de conciliación, representar a los denunciantes ante los tribunales, y actuar como amicus curiae o experto. Lo que se pretende con todo ello es que realmente los organismos tengan capacidad de investigación, de actuación en los procedimientos judiciales y que se conviertan en una referencia a la que acudir para las víctimas.

No puede obviarse que la consolidación progresiva del derecho antidiscriminatorio por razón de raza o étnica es ya imparable, aunque pueda continuar aprendiendo de las medidas adoptadas respecto a otros motivos, por ejemplo, en el ámbito de la discriminación por razón de género. Para avanzar es imprescindible reforzar los estándares jurisprudenciales, en la dirección ya marcada, y completarlos con órganos para la igualdad autónomos e independientes. Hay que superar la idea de que el racismo y la discriminación no existen (o solo mínimamente y de forma puntual) porque precisamente ambos se alimentan de su negación y de la falta de voluntad correlativa para combatirlos, es necesaria una oposición activa. Se trata, en definitiva, de insistir en un tratamiento holístico que permita luchar contra la discriminación racial o étnica siendo preventivo y que ponga en el centro del mismo a las víctimas. Así puede evidenciarse la prioridad en los Estados democráticos del principio de igualdad, para no seguir admitiendo un racismo líquido o encubierto que pretende convivir con los valores de la democracia, pero es radicalmente incompatible con ellos.

\section{Bibliografía}

Ahedo, A. M. (2017). Recientes Políticas de Inmigración e Integración en los Países Nórdicos. Dinámicas transnacionales y discursos nacionales ante la inmigración forzada y económica. Relaciones Internacionales, 36, pp. 11-30.

Aguilar, M. J. (2014). Discriminaciones múltiples de los migrantes en perspectiva de derechos, BARATARIA. Revista Castellano-Manchega de Ciencias Sociales, 17, pp. 39-54.

Ammer, M., Crowley, N., Liegl, B., Holzleithner, E., Wladasch, K. and Yesilkagit, K. (2010). Study on equality bodies set up under Directives 2000/43/EC, 2004/113/EC, and 2006/54/EC. Synthesis report, Utrecht, The Netherlands, Vienna, Austria: Human European Consultancy \& Ludwig Boltzmann Institute.

Añón, M. J. (2015). Discriminación racial: el racismo institucional desvelado. En F. Arcos (ed.), La Justicia y los Derechos Humanos en un mundo globalizado (pp. 133-165). Madrid, España: Dykinson.

Balibar, E. (1991). ¿Existe el neorracismo?. En I. Wallerstein y E. Balibar (eds.), Raza, Nación y Clase (pp. 31-48). Madrid: IEPALA.

Barrère, M. A. (2010). La interseccionalidad como desafío al mainstreaming de género en las políticas públicas. Revista Vasca de Administración Pública. HerriArduralaritzako Euskal Aldizkaria, 87-88, pp. 225-252.

Beck, U. (2006). La sociedad del riesgo: hacia una nueva modernidad, Barcelona: Paidós Ibérica.

Bergmann, E. (2017). Nordic Nationalism and Right-Wing Populist Politics: Imperial Relationships and National Sentiments. London, UK: Palgrave Macmillan, Springer Nature.

Bobbio, N. (2010). La naturaleza del prejuicio. Racismo, hoy. Iguales y diferentes. En D. Caicedo y A. Porras (eds.), Igualdad y no discriminación. El reto de la diversidad (pp. 183-215). Quito, Ecuador: Ministerio de Justicia, Derechos Humanos y Cultos. 
Cachón, L. (2004). España y la Directiva 2000/43: de la "ocasión perdida" a una legislación general sobre igualdad de trato. Tiempo de Paz, 73, pp. 13-22.

Carens, J. H. (2013). The Ethics of Immigration. New York, USA: Oxford University Press.

Cavalli-Sforza, L. L. (1997). Genes, pueblos y lenguas. Barcelona, España: Crítica.

Casado, L. (2012). Discriminación racial y ejercicio del derecho a la instrucción en la jurisprudencia del Tribunal Europeo de Derechos. Revista Vasca de Administración Pública. Herri-Arduralaritzako Euskal Aldizkaria, 92, pp. 247-291.

Casado, L. (2013). Recopilación y documentación de asuntos tramitados ante el Tribunal Europeo de Derechos Humanos en casos relacionados con la discriminación por motivos raciales, étnicos o por razón de nacionalidad. En J. García Añón y M. Ruiz (coords.), Discriminación racial y étnica: balance de la aplicación y eficacia de las garantías normativas (pp. 57-148), Valencia, España: Tirant lo Blanch.

Cea D’Ancona, $\mathrm{M}^{\mathrm{a}}$. A. (2015). Los efectos de la crisis económica en la molduración y evolución de la opinión pública española ante la inmigración. Migraciones, 37, pp. 29-52.

Cobreros, E. (2007). Discriminación por indiferenciación, estudio y propuesta. Revista Española de Derecho Constitucional, 81, pp. 71-114.

Cormack, J. and Bell, M. (2005). Developing Anti-Discrimination Law in Europe. The 25 EU member States compared, Brussels: European network of independent experts in the antidiscrimination field (European Human Consultancy Migration Policy Group).

De Lucas, J. (2012). Sobre los fundamentos de la igualdad y del reconocimiento. Un análisis crítico de las condiciones de las políticas europeas de integración ante la inmigración. En VV. AA., Inmigración e integración en la UE. Dos retos para el siglo XXI (pp. 11-91). Bilbao, España: X Premio Francisco Javier de Landaburu Universitas, Eurobask.

Dworkin, R. (1985). A Matter of Principle. Cambridge, MA: Harvard University Press.

Esteve, F. (2013). La normativa europea contra la discriminación y el racismo: su desarrollo y aplicación en España, Italia y Francia. En J. García Añón y M. Ruiz (coords.), Discriminación racial y étnica: balance de la aplicación y eficacia de las garantías normativas (pp. 25-56). Valencia, España: Tirant lo Blanch.

Esteve, F. (2019). Alcance de las obligaciones internacionales y europeas contra la discriminación racial y sus implicaciones para España. Anuario de los cursos de derechos humanos de Donostia-San Sebastián, XVIII, pp. 87-137.

Kendi, I. X. (2019). How to be an antiracist. New York, United States: One World, Penguin Random House LLC.

García Añón, J. (2013). Discriminación, exclusión social y conflicto en sociedades multiculturales: la identificación por perfil étnico. En J. García Añón y M. Ruiz (coords.), Discriminación racial y étnica: balance de la aplicación y eficacia de las garantías normativas (pp. 280-316). Valencia, España: Tirant lo Blanch.

Gil, J. M ${ }^{a}$. (2017). En torno al artículo 14 de la CEDH: concepto, jurisprudencia y nuevos desafíos de (y ante) el Consejo de Europa. Quaestio luris, 10(02), pp. 919-954.

Gracia, J. y Jiménez, D. (coords.) (2016). Tristes tópicos. Representaciones Sociales desenfocadas. Zaragoza, España: Laboratorio de Sociología Jurídica, Universidad de Zaragoza.

Kymlicka, W. (2016). Defending diversity in an era of populism: multiculturalism and interculturalism compared. En N. Meer, T. Modood and R. Zapata-Barrero (eds.), Interculturalism and multiculturalism: debating the dividing lines (pp. 158-177). Edinburgh, Scotland: University Press Edinburgh.

Laclau, E. (2005). La razón populista. Buenos Aires, Argentina: Fondo de Cultura Económica. 
Laclau, E. (2009). Populismo ¿qué nos dice el nombre?. En F. Panizza (comp.), El populismo como espejo de la democracia (pp. 51-70). Buenos Aires, Argentina: Fondo de Cultura Económica

Laclau, E. y Mouffe, Ch. (1987). Hegemonía y estrategia socialista. Hacia una radicalización de la democracia. México: Siglo XXI.

Lousada, J. F. (2017). Discriminación múltiple: el estado de la cuestión y algunas reflexiones. AequAlitaS, 41, pp. 29-40.

Lucak, N. (2012). Georgia v. Russia Federation: A Question of the Jurisdiction of the International Court of Justice. Maryland Journal of International Law, 27(1), article 18, pp. 323-354.

Márquez, C. (2015). La implementación de los principios rectores de las Naciones Unidas sobre empresas y Derechos Humanos por medio de los planes nacionales de acción. Revista de Responsabilidad Social de la Empresa, 20, pp. 55-87.

Mezzadra, S. y Nielson, B. (2014). Fronteras de inclusión diferencial. Subjetividad y luchas en el umbral de los excesos de justicia. Papeles del CEIC, 2, 30 pp.

Mouffe, Ch. (2007). En torno a lo político. Buenos Aires, Argentina: Fondo de Cultura Económica.

Parekh, B. (2005). Repensando el multiculturalismo. Diversidad cultural y teoría política. Madrid, España: Istmo.

Rey, F. (2008). La discriminación múltiple, una realidad antigua, un concepto nuevo. Revista española de derecho constitucional, 84, pp. 251-283.

Rey, F. (2012). La discriminación racial en la jurisprudencia del Tribunal Europeo de Derechos Humanos. Pensamiento Constitucional, 17, pp. 291-319.

Rey, F. (2017). Igualdad y prohibición de discriminación: de 1978 a 2018. UNED. Revista de Derecho Político, 100, pp. 125-171.

Sassen, S. (2010). Territorio, autoridad y derechos. De los ensamblajes medievales a los ensamblajes globales. Madrid, España: Katz Editores.

Sckiek, D. (2002). A New Framework on Equal Treatment of Persons in EC Law?. European Law Journal, 8(2), pp. 290-314.

Simon, P. W. A. and Beaujeu, M. (2018). Mainstreaming and redefining the immigrant integration debate in old migration countries: a case study of France, the UK and the Netherlands. En P. Scholten and I. Van Breugel (eds.), Mainstreaming Integration Governance. New Trends in Migrant Integration Policies in Europe (pp. 25-46). Switzerland: Palgrave Macmillan.

Solanes, A. (2016). Empresas y derechos humanos: sobre la responsabilidad social de las empresas en el ámbito internacional y nacional. En VV. AA., Empresas, Derechos Humanos y RSC: Una mirada holística desde las Ciencias Sociales y Jurídicas (pp. 291-326). Navarra, España: Cizur Menor, Thomson Reuters Aranzadi.

Solanes, A. (2017). Acomodo razonable en Canadá y discriminación indirecta en Europa como garantía del principio de igualdad. Anales de la Cátedra Francisco Suárez, 51, pp. 305-333.

Solanes, A. (2018). Derechos de los extranjeros en España. En J. De Lucas y J. M. Rodríguez (coords.), Derechos humanos y Constitución (pp. 263-286). Valencia, España: Tirant lo Blanch.

Subirats, J. (2010). Si la respuesta es gobernanza, ¿cuál es la pregunta? Factores de cambio en la política y en las políticas. Ekonomiaz, 74, pp. 16-35.

Tejada, M. (2013). El avance de la xenofobia en Europa. Madrid, España: Documentos de Debate, Fundación Ideas.

Triadafilopoulos, T. (2011). Illiberal means to liberal ends? Understanding recent immigrant integration policies in Europe. Journal of Ethnic and migration Studies, 37(6), pp. 861-880. 
Villavicencio, P. (2018). Igualdad, Derechos Humanos y Objetivos de Desarrollo Sostenible ¿Aprender de la experiencia o tropezar con la misma piedra?. Derechos y Libertades, 38, pp. 389-425.

Vallespín, F. y Bascuñán, M. M., (2017). Populismos. Madrid, España: Alianza Editorial.

Waldron, J. (2012). The harm in hate speech. Cambridge, Massachusetts, London, England: Harvard University Press. 